Research Article

\title{
Free Vibration Analysis of Composite Conical Shells with Variable Thickness
}

\author{
Saira Javed $\mathbb{D}^{1}{ }^{1}$ F. H. H. Al Mukahal $\mathbb{D}^{1},{ }^{1}$ and M. A. Salama $\mathbb{D}^{2}$ \\ ${ }^{1}$ Department of Mathematics and Statistics, College of Science, King Faisal University, P. O. Box 400, Hofuf 31982, Saudi Arabia \\ ${ }^{2}$ Deanship of Common First Year, Jouf University, Sakaka, Saudi Arabia \\ Correspondence should be addressed to F. H. H. Al Mukahal; fatemah.almukahal@gmail.com
}

Received 4 December 2017; Revised 13 March 2018; Accepted 26 October 2019; Published 14 February 2020

Academic Editor: Toshiaki Natsuki

Copyright (c) 2020 Saira Javed et al. This is an open access article distributed under the Creative Commons Attribution License, which permits unrestricted use, distribution, and reproduction in any medium, provided the original work is properly cited.

Free vibration of conical shells of variable thickness is analysed under shear deformation theory with simply supported and clamped free boundary conditions by applying collocation with spline approximation. Sinusoidal thickness variation of layers is assumed in axial direction. Displacements and rotational functions are approximated by Bickley-type splines of order three and a generalized eigenvalue problem is obtained. This problem is solved numerically for an eigenfrequency parameter and an associated eigenvector of spline coefficients. The vibration of composite conical shells consisting of three layers and five layers where each layer is made up of different materials is analysed. Parametric studies are made for analysing the frequencies of the shell with respect to the coefficients of thickness variations, length ratio, cone angle, circumferential node number, and different ply angles with different combinations of the materials. The results are presented in terms of tables and graphs.

\section{Introduction}

Laminated composite materials are widely used in engineering applications, since they have the ability to achieve desired weight as they have higher specific modulus and specific strength. Moreover, composite materials can tailor the mechanical properties. The strength and deformation of composite structural elements are influenced by ply orientation, stacking sequence, and material properties. The main aim of the designer is to control the unwarranted vibration, which in return leads to the failure of the structure. Thus, conical shell structures are source of attraction for most of the contemporary engineers for being stiffer structural element in modern construction. Conical shells structures have a wide range of applications in the fields of aviation, ship building, rocket, missile, and chemical industry.

Complex shells of variable thickness were examined by Kang [1]. Moreover, conical shells of variable thickness were investigated using the Haar wavelet method by Cao et al. [2]. Akbari et al. [3] studied the conical panels consisting of functionally graded materials using the generalized differential quadrature method. Similarly, the generalized differential quadrature method was used by Bacciocchi et al. [4] to analyse the vibration of plates of variable thickness and shells. A novel vibrational numerical method was used by Ansari et al. [5] to investigate the free vibration of composite conical shells. 2D-FGM truncated conical shell resting on Winkler-Pasternak foundations was studied by Asanjarani et al. [6] using the differential quadrature method for different boundary conditions. Domain decomposition method was used by $\mathrm{Wu}$ et al. [7] to analyse the free vibration of laminated conical shells resting on Pasternak foundation. Fluid loaded ring-stiffened conical shells of variable thickness were analysed for their free vibration using the transfer matrix method by Liu et al. [8]. Nejad et al. [9] investigated truncated conical shells having functionally graded materials with axially varying properties under nonuniform pressure. Singular convolution method was used to analyse the vibration of composite conical shells under shear deformation theory [10]. Analytical and experimental study for the free vibration of joined conical shells was carried out by Shakouri and Kouchakzadeh [11]. Galerkin method was used by Sofiyev and Kuruoglu [12] to find the solution of buckling of conical shells. Spline method 
was used to analyse the free vibration of symmetric and antisymmetric angle-ply conical shells [13-15]. Moreover, Javed et al. $[16,17]$ investigated conical shells and plates using the spline method. The Haar wavelet method was used by Xie et al. [18] to investigate the free vibration of conical shells and annular plates. Ma et al. [19] studied the free and forced vibration of coupled conical-cylindrical shells using the Fourier-Ritz method. Furthermore, Fourier-Ritz method was used to analyse the vibrations of composite laminated circular panels and shells of revolution by Wang et al. [20]. Su et al. [21] analysed the 3D vibration of conical shells, cylindrical shells, and annular plates. Transfer matrix method was used to study the structural and acoustic response of conical shells by Wang et al. [22]. Composite laminated shells were studied using unified formulation including shear deformation by $\mathrm{Qu}$ et al. [23]. Wu and Lee [24] studied conical shells of variable thickness using differential quadrature method and Sivadas and Ganesan [25] used finite element method to analyse cones of variable thickness. Moreover, variable thickness of loudspeaker cone significantly affects the performance of the loud speaker [26]. In addition, variable thickness also affects the performance and efficiency of radome and ballistic missile [27, 28].

The displacement and rotational functions are approximated using cubic spline and collocation procedure is applied to obtain a set of field equations. The field equations along with the equations of boundary conditions yield a system of homogeneous simultaneous algebraic equations on the assumed spline coefficients, resulting in generalized eigenvalue problem. This eigenvalue problem is solved using eigensolution technique to get many eigenfrequencies as we required [29]. The effects of frequency parameters with respect to the coefficient of thickness variations, cone angle, aspect ratio, circumferential node number, boundary conditions, and three types of layered materials with three- and five-layered conical shells are presented and discussed.

\section{Formulation of the Problem}

Laminated conical shell frusta of variable thickness along axial direction having arbitrary number of layers, which are perfectly bonded together, are shown in Figure 1 . The orthogonal coordinate system $(x, \theta, z)$ is fixed at its reference surface, which is taken to be at the middle surface. The radius of the cone at any point along its length is $r=x \sin \alpha$. The radius at the small end of the cone is $r_{a}=a \sin \alpha$ and the other end is $r_{b}=b \sin \alpha$. $\alpha$ is the semivertical angle and $\ell$ is the length of the cone along its generator [30].

The displacement components are assumed to be of the form in [31]:

$$
\begin{aligned}
u(r, \theta, z, t) & =u_{0}(r, \theta, t)+z \psi_{x}(r, \theta, t), \\
v(r, \theta, z, t) & =v_{0}(r, \theta, t)+z \psi_{\theta}(r, \theta, t), \\
w(r, \theta, z, t) & =w_{0}(r, \theta, t)
\end{aligned}
$$

where $u, v$, and $w$ are the displacement functions in $x, \theta$, and $z$ directions, respectively, $u_{0}, v_{0}$, and $w_{0}$ are the displacements of the middle surface of the cone, and $\psi_{x}$ and $\psi_{\theta}$ are shear rotations of any point on the middle surface of the cone.

The thickness variation of the $k$-th layer of the shell is assumed to be of the form

$$
h_{k}(x)=h_{0 k} g(x) \text {, }
$$

where $h_{0 k}$ is a constant thickness, and

$$
g(x)=C_{s} \sin \pi\left(\frac{x-a}{\ell}\right)
$$

where $C_{s}$ are the coefficients of sinusoidal variation.

The thickness of the shell becomes uniform when $g(x)=1$.

Since the thickness is assumed to be varying along the axial direction, one can define the elastic coefficients $A_{i j}, B_{i j}$, and $D_{i j}$ (extensional, bending-extensional coupling, and bending stiffnesses) corresponding to layers of uniform thickness with superscript " $c$ " as

$$
\begin{aligned}
& A_{i j}=A_{i j}^{c} g(x), \\
& B_{i j}=B_{i j}^{c} g(x), \\
& D_{i j}=D_{i j}^{c} g(x), \\
& A_{i j}^{c}=\sum_{k} \bar{Q}_{i j}^{(k)}\left(z_{k}-z_{k-1}\right), \\
& B_{i j}^{c}=\frac{1}{2} \sum_{k} \bar{Q}_{i j}^{(k)}\left(z_{k}^{2}-z_{k-1}^{2}\right), \\
& D_{i j}^{c}=\frac{1}{3} \sum_{k} \bar{Q}_{i j}^{(k)}\left(z_{k}^{3}-z_{k-1}^{3}\right), \quad \text { for } \quad i, j=1,2,6, \\
& A_{i j}^{c}=K \sum_{k} \bar{Q}_{i j}^{(k)}\left(z_{k}-z_{k-1}\right), \quad \text { for } \quad i, j=4,5 .
\end{aligned}
$$

Here $K$ is the shear correction factor, $z_{k-1}$ and $z_{k}$ are the boundaries of the $k$-th layer, and the quantities $\bar{Q}_{i j}^{(k)}$ are defined in [32]. In the case of symmetric angle-ply lamination, the laminate stiffnesses $A_{16}, A_{26}, D_{16}, D_{26}, A_{45}$ and all $B_{i j}$ are identically zero.

The governing differential equations characterising the vibration of conical shell frusta of variable thickness including first-order shear deformation theory are derived in terms of displacement functions $u_{0}(x, \theta, t), v_{0}(x, \theta, t)$, and $w_{0}(x, \theta, t)$ and shear rotational functions $\psi_{x}(x, \theta, t)$ and $\psi_{\theta}(x, \theta, t)$ using stress-strain and strain-displacement relations of the conical shell.

The displacement components $u_{0}, v_{0}$, and $w$ and shear rotations $\psi_{x}$ and $\psi_{\theta}$ are assumed in separable form given as

$$
\begin{aligned}
& u_{0}(x, \theta, t)=U(x) \cos n \theta e^{i \omega t}, \\
& v_{0}(x, \theta, t)=V(x) \sin n \theta e^{i \omega t}, \\
& w(x, \theta, t)=W(x) \cos n \theta e^{i \omega t}, \\
& \psi_{x}(x, \theta, t)=\Psi_{x}(x) \cos n \theta e^{i \omega t}, \\
& \psi_{\theta}(x, \theta, t)=\Psi_{\theta}(x) \sin n \theta e^{i \omega t},
\end{aligned}
$$




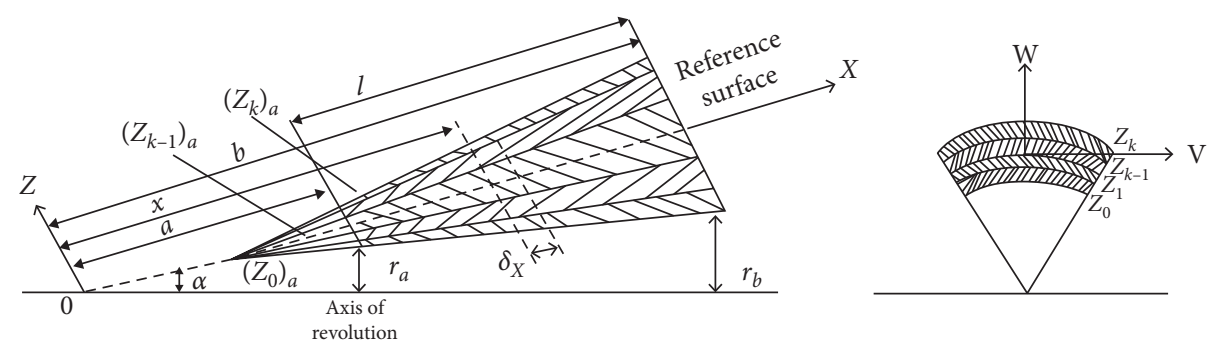

FIGURE 1: Layered conical shell of variable thickness: geometry.

where $\omega$ is the angular frequency of vibration, $t$ is the time, and $n$ is the circumferential node number.

Incorporating (5) into the governing differential equations, the resulting equation becomes in the matrix form as

$$
\left[\begin{array}{lllll}
L_{11} & L_{12} & L_{13} & L_{14} & L_{15} \\
L_{21} & L_{22} & L_{23} & L_{24} & L_{25} \\
L_{31} & L_{32} & L_{33} & L_{34} & L_{35} \\
L_{41} & L_{42} & L_{43} & L_{44} & L_{45} \\
L_{51} & L_{52} & L_{53} & L_{54} & L_{55}
\end{array}\right]\left\{\begin{array}{c}
U \\
V \\
W \\
\psi_{X} \\
\psi_{\Theta}
\end{array}\right\}=\left\{\begin{array}{c}
0 \\
0 \\
0 \\
0 \\
0
\end{array}\right\},
$$

where $L_{i j}$ are the differential operators and they depend on the variable $x$ only and are given in [14].

The nondimensional parameters are introduced to modify the above equations as follows:

$$
\begin{aligned}
& X=\frac{x-a}{l}, \quad a \leq x \leq b, X \in[0,1], \\
& \lambda=e \lambda^{\prime},
\end{aligned}
$$

where $\lambda$ is a frequency parameter, and

$$
\begin{gathered}
\gamma=\frac{h_{0}}{r_{a}}, \\
\gamma^{\prime}=\frac{h_{0}}{a},
\end{gathered}
$$

where $\gamma$ are ratios of thickness to radius and to a length, and

$$
\beta=\frac{a}{b},
$$

where $\beta$ is a length ratio.

$$
\delta_{k}=\frac{h_{k}}{h},
$$

where $\delta$ is the relative layer thickness of the $k$-th layer.

The new set of differential equations is obtained and given in the new set of matrix form as

$$
\left[\begin{array}{lllll}
L_{11}^{*} & L_{12}^{*} & L_{13}^{*} & L_{14}^{*} & L_{15}^{*} \\
L_{21}^{*} & L_{22}^{*} & L_{23}^{*} & L_{24}^{*} & L_{25}^{*} \\
L_{31}^{*} & L_{32}^{*} & L_{33}^{*} & L_{34}^{*} & L_{35}^{*} \\
L_{41}^{*} & L_{42}^{*} & L_{43}^{*} & L_{44}^{*} & L_{45}^{*} \\
L_{51}^{*} & L_{52}^{*} & L_{53}^{*} & L_{54}^{*} & L_{55}^{*}
\end{array}\right]\left\{\begin{array}{c}
U \\
V \\
W \\
\ell \Psi_{X} \\
\ell \Psi_{\theta}
\end{array}\right\}=\left\{\begin{array}{c}
0 \\
0 \\
0 \\
0 \\
0
\end{array}\right\} .
$$
[14].

The differential operators $L_{i j}^{*}$ of the matrix are given in
The following range of thickness coefficient is considered:

$$
-0.5 \leq C_{s} \leq 0.5 \text {. }
$$

2.1. Spline Collocation Procedure. The displacement functions $U, V$, and $W$ and rotational functions $\Psi_{X}$ and $\Psi_{\Theta}$ are approximated by cubic spline functions in the range of $X \in[0,1]$ as given in $[30]$.

$$
\begin{aligned}
U^{*}(X) & =\sum_{i=0}^{2} a_{i} X^{i}+\sum_{j=0}^{N-1} b_{j}\left(X-X_{j}\right)^{3} H\left(X-X_{j}\right), \\
V^{*}(X) & =\sum_{i=0}^{2} c_{i} X^{i}+\sum_{j=0}^{N-1} d_{j}\left(X-X_{j}\right)^{3} H\left(X-X_{j}\right), \\
W(X) & =\sum_{i=0}^{2} e_{i} X^{i}+\sum_{j=0}^{N-1} f_{j}\left(X-X_{j}\right)^{3} H\left(X-X_{j}\right), \\
\Psi_{X}^{*}(X) & =\sum_{i=0}^{2} g_{i} X^{i}+\sum_{j=0}^{N-1} p_{j}\left(X-X_{j}\right)^{3} H\left(X-X_{j}\right), \\
\Psi_{\Theta}^{*}(X) & =\sum_{i=0}^{2} l_{i} X^{i}+\sum_{j=0}^{N-1} q_{j}\left(X-X_{j}\right)^{3} H\left(X-X_{j}\right) .
\end{aligned}
$$

Here, $H\left(X-X_{j}\right)$ is the Heaviside step functions. The range of $X$ is divided into $N$ subintervals at the points $X=X_{s}$, $s=1,2,3, \ldots, N-1$. The width of each subinterval is $1 / N$ and $X_{s}=s / N(s=0,1,2, \ldots, N)$, since the knots $X_{s}$ are chosen to be equally spaced.

The assumed spline functions given in (14) are approximated at the nodes (coincide with the knots) and these splines satisfy the differential equations given in (12) at all $X_{s}$, resulting in the homogeneous system of $(5 N+5)$ equations in the $(5 N+15)$ unknown spline coefficients. To get 10 more equations, the following boundary conditions are considered in this problem:

(i) Clamped-free (C-F) (one end is clamped and the other is free)

(ii) Simply supported (S-S) (both ends are simply supported)

Combining these 10 equations with the earlier $(5 N+5)$ equations, one can get $(5 N+15)$ homogeneous equations, so the number of equations coincides with the number of unknowns. Thus, we get a generalized eigenvalue problem in the form 


$$
[M]\{q\}=\lambda^{2}[P]\{q\},
$$

where $[M]$ and $[P]$ are the square matrices, $\{q\}$ is the column matrix of the spline coefficients, and $\lambda$ is the eigenfrequency parameter.

\section{Results and Discussions}

A convergence study was carried out for frequency parameter $\lambda$. The number of knots $N$ of the spline function was set at 14 after a number of convergence trials.

In the present work, frequency of symmetric angle-ply conical shells is analysed with respect to the circumferential node number, length ratio, cone angle, sinusoidal thickness variation and different number of lay ups, material combinations, and ply angles for C-F and S-S boundary conditions. Three materials, AS4/3501-6 graphite/epoxy (GE), E-glass/epoxy (EGE), and Kevlar-49/epoxy (KE), are considered to analyse the problem.

Table 1 shows the effect of circumferential node number $n$ on the fundamental frequency parameter $\lambda$ of three- and five-layered shells having ply angles of $45^{\circ} / 0^{\circ} / 45^{\circ}$ (KE/EGE/ $\mathrm{KE}$ ) and $45^{\circ} / 60^{\circ} / 0^{\circ} / 60^{\circ} / 45^{\circ}$ (KE/EGE/GE/EGE/KE) for C-F and S-S boundary conditions, respectively. The parameters $\beta=0.5, \gamma=0.05, \alpha=30^{\circ}$, and $C_{s}=0.5$ are fixed. It can be seen from the results that three-layered shells show higher frequency than five-layered shells. Moreover, the fundamental frequency value is lower for C-F boundary conditions than for S-S boundary conditions.

The effect of circumferential node number $n$ on the fundamental frequency parameter $\lambda$ of three- and five-layered shells having ply angles of $45^{\circ} / 30^{\circ} / 0^{\circ} / 30^{\circ} / 45^{\circ}$ for S-S boundary conditions is shown in Table 2 . The parameters $\beta=0.5, \gamma=0.05, \alpha=30^{\circ}$, and $C_{s}=0.5$ are fixed. Different combinations of materials are used and, from the results, it can be seen that three-layered shells consisting of GE/EGE/ GE show highest frequency followed by KE/EGE/KE and GE/KE/GE material combinations. Moreover, five-layered shells consisting of GE/EGE/KE/EGE/GE show highest frequency followed by KE/EGE/GE/EGE/KE and EGE/GE/ $\mathrm{KE} / \mathrm{GE} / \mathrm{EGE}$ material combinations.

The effect of sinusoidal thickness variation $C_{s}$ on the fundamental frequency parameter $\lambda$ is depicted in Table 3 for three- and five-layered shells having ply angles of $45^{\circ} / 0^{\circ} \%$ $45^{\circ}$ and $45^{\circ} / 60^{\circ} / 0^{\circ} / 60^{\circ} / 45^{\circ}$ for C-F and S-S boundary conditions. The parameters $\beta=0.5, \gamma=0.05, \alpha=30^{\circ}$, and $n=4$ are fixed. The results concluded that the value of the frequency parameter decreases with the increase of number of layers. Moreover, there is a marginal difference in the values of the frequency parameter with the increase of sinusoidal thickness variation.

Figure 2 describes the variation of angular frequencies $\omega$ with respect to the length ratio $\beta$ of five-layered conical shells having material sequence as $\mathrm{KE} / \mathrm{EGE} / \mathrm{GE} / \mathrm{EGE} / \mathrm{KE}$ with ply angles of (a) $45^{\circ} / 30^{\circ} / 0^{\circ} / 30^{\circ} / 45^{\circ}$, (b) $45^{\circ} / 60^{\circ} / 0^{\circ} / 60^{\circ} / 45^{\circ}$, and (c) $30^{\circ} / 60^{\circ} / 0^{\circ} / 60^{\circ} / 30^{\circ}$ for S-S boundary conditions. The parameters cone angle $\alpha=50^{\circ}$, ratio of thickness to radius $\gamma=0.05$, sinusoidal thickness variation $C_{s}=0.3$, and circumferential node number $n=4$ are fixed. Figures 2(a)-2(c) relate to the sinusoidal thickness variation. It is seen from the figures that the frequencies monotonically increase with increase in $\beta$, that is, with decreasing cone length. Since the frequency increases, it shows that the rigidity of the structure increases. The increase of $\omega_{m}(m=1,2,3)$ is gradual and steady up to $0.1 \leq \beta \leq 0.6$, and there is a rapid increase afterwards. For very short shells $(\beta>0.8)$, frequencies are very high.

The variation of angular frequency $\omega_{m}(m=1,2,3)$ with length ratio $\beta$ for three-layered conical shell under S-S boundary conditions is shown in Figures 3(a) as $30^{\circ} / 0^{\circ} / 30^{\circ}$, 3 (b) as $45^{\circ} / 0^{\circ} / 45^{\circ}$, and $3(\mathrm{c})$ as $60^{\circ} / 0^{\circ} / 60^{\circ}$ with material combination as GE/EGE/GE. The fixed parameters and curvature of the curves are the same as seen in Figure 2 but the angular frequency differs with layup and lamination angle.

Figure 4 represents the variation of frequency parameter $\lambda_{m}(m=1,2,3)$ with respect to the cone angle $\alpha$ for threelayered shells with angles of $30^{\circ} / 0^{\circ} / 30^{\circ}, 45^{\circ} / 0^{\circ} / 45^{\circ}$, and $60^{\circ} / 0^{\circ} \%$ $60^{\circ}$ using GE/EGE/GE materials for S-S boundary conditions. The other parameters $\beta, \gamma^{\prime}, n$, and $C_{s}$ are fixed. The value of frequency parameter decreases as the cone angle increases; the decrease is strict within $10^{\circ} \leq \alpha \leq 30^{\circ}$ and steady afterwards. The value of $\lambda_{m}(m=1,2,3)$ increases with the increase of lamination angle.

Five-layered conical shells are considered in Figure 5 to see the effect of cone angle on the value of frequency parameter under S-S boundary condition. It is seen that there is a significant decrease in frequency value for $10^{\circ} \leq \alpha \leq 30^{\circ}$ and the value decreases almost linearly within $30^{\circ} \leq \alpha \leq 90^{\circ}$.

Three-layered conical shells with three different material combinations are considered in Figure 6 to analyse the effect of different cone angles on the frequency parameter. It is seen that frequency parameter value increases with the increase of ply angle. The difference in the frequency value for three different ply angles is more within $10^{\circ} \leq \alpha \leq 30^{\circ}$ and the difference becomes lesser within $30^{\circ} \leq \alpha \leq 90^{\circ}$. Moreover, the frequency parameter value differs for different lamination material schemes.

Effect of cone angle on the fundamental frequency parameter value of five-layered shells with different material combinations and ply orientations is shown in Figure 7 for S-S boundary conditions. It can be seen from Figures $7(a)$ and $7(\mathrm{c})$ that ply orientation of $45^{\circ} / 60^{\circ} / 0^{\circ} / 60^{\circ} / 45^{\circ}$ depicts highest fundamental frequency parameter value followed by $45^{\circ} / 30^{\circ} / 0^{\circ} / 30^{\circ} / 45^{\circ}$ and $30^{\circ} / 60^{\circ} / 0^{\circ} / 60^{\circ} / 30^{\circ}$. Meanwhile, in Figure $7(\mathrm{~b})$, ply orientation of $45^{\circ} / 60^{\circ} / 0^{\circ} / 60^{\circ} / 45^{\circ}$ depicts highest fundamental frequency parameter value followed by $30^{\circ} / 60^{\circ} / 0^{\circ} / 60^{\circ} / 30^{\circ}$ and $45^{\circ} / 30^{\circ} / 0^{\circ} / 30^{\circ} / 45^{\circ}$. In addition to this material combination, EGE/GE/KE/GE/EGE shows highest frequency followed by GE/EGE/KE/EGE/GE and KE/EGE/ GE/EGE/KE material combinations.

Figure 8 shows the effect of length ratio on the fundamental angular frequency value under S-S boundary condition of three-layered shells with different materials and ply orientations. It can be seen that, with the increase of length ratio, the angular frequency increases. Moreover, it can be seen from Figures 8(a)-8(c) that there is little difference in the angular frequency value for three different ply 
TABLE 1: Influence of circumferential node number on the fundamental frequency parameter of three- and five-layered conical shells with $\mathrm{KE} / \mathrm{EGE} / \mathrm{KE}$ and $\mathrm{KE} / \mathrm{EGE} / \mathrm{GE} / \mathrm{EGE} / \mathrm{KE}$ material combinations.

\begin{tabular}{|c|c|c|c|c|}
\hline \multirow[b]{2}{*}{$n$} & \multicolumn{2}{|c|}{ C-F } & \multicolumn{2}{|c|}{ S-S } \\
\hline & $\begin{array}{c}45^{\circ} / 0^{\circ} / 45^{\circ} \\
\mathrm{KE} / \mathrm{EGE} / \mathrm{KE} \\
\end{array}$ & $\begin{array}{c}45^{\circ} / 60^{\circ} / 0^{\circ} / 60^{\circ} / 45^{\circ} \\
\text { KE/EGE/GE/EGE/KE }\end{array}$ & $\begin{array}{c}45^{\circ} / 0^{\circ} / 45^{\circ} \\
\mathrm{KE} / \mathrm{EGE} / \mathrm{KE}\end{array}$ & $\begin{array}{c}45^{\circ} / 60^{\circ} / 0^{\circ} / 60^{\circ} / 45^{\circ} \\
\mathrm{KE} / \mathrm{EGE} / \mathrm{GE} / \mathrm{EGE} / \mathrm{KE} \\
\end{array}$ \\
\hline 1 & 0.330183 & 0.283127 & 0.400495 & 0.336936 \\
\hline 2 & 0.333685 & 0.309334 & 0.654284 & 0.566468 \\
\hline 3 & 0.213942 & 0.200907 & 0.560153 & 0.454850 \\
\hline 4 & 0.165313 & 0.156536 & 0.443432 & 0.375673 \\
\hline 5 & 0.170269 & 0.158292 & 0.431779 & 0.372236 \\
\hline 6 & 0.202314 & 0.185803 & 0.497189 & 0.426926 \\
\hline 7 & 0.243201 & 0.223443 & 0.600570 & 0.514700 \\
\hline 8 & 0.285948 & 0.264548 & 0.725938 & 0.622380 \\
\hline 9 & 0.327225 & 0.306138 & 0.867462 & 0.744432 \\
\hline 10 & 0.363870 & 0.345774 & 1.022135 & 0.878158 \\
\hline
\end{tabular}

TABLE 2: Influence of circumferential node number on the fundamental frequency parameter of three- and five-layered conical shells with different material combinations.

\begin{tabular}{lcccccc}
\hline$n$ & \multicolumn{3}{c}{$45^{\circ} / 0^{\circ} / 45^{\circ}$} & & \multicolumn{4}{c}{$45^{\circ} / 30^{\circ} / 0^{\circ} / 30^{\circ} / 45^{\circ}$} \\
KE/EGE/KE & GE/KE/GE & GE/EGE/GE & KE/EGE/GE/EGE/KE & EGE/KE/GE/EGE & GE/EGE/KE/EGE/GE \\
\hline 1 & 0.400495 & 0.373850 & 0.421468 & 0.307091 & 0.304765 & 0.36881 \\
2 & 0.654284 & 0.597870 & 0.690709 & 0.490737 & 0.476702 & 0.59392 \\
3 & 0.560153 & 0.520425 & 0.602290 & 0.415691 & 0.341499 & 0.51378 \\
4 & 0.443432 & 0.422939 & 0.469940 & 0.352047 & 0.325831 & 0.42872 \\
5 & 0.431779 & 0.412458 & 0.463464 & 0.346254 & 0.361600 & 0.43013 \\
6 & 0.497189 & 0.472720 & 0.540390 & 0.391703 & 0.429708 & 0.49925 \\
7 & 0.600570 & 0.569328 & 0.656000 & 0.468217 & 0.516727 & 0.60416 \\
8 & 0.725938 & 0.686551 & 0.794530 & 0.563476 & 0.616703 & 0.73039 \\
9 & 0.867462 & 0.818499 & 0.950241 & 0.672017 & 0.727056 & 0.87226 \\
10 & 1.022135 & 0.962222 & 1.119930 & 0.791223 & 1.02683 \\
\hline
\end{tabular}

TABLE 3: Influence of sinusoidal thickness variation on the fundamental frequency parameter of three- and five-layered conical shells with $\mathrm{KE} / \mathrm{EGE} / \mathrm{KE}$ and $\mathrm{KE} / \mathrm{EGE} / \mathrm{GE} / \mathrm{EGE} / \mathrm{KE}$ material combinations.

\begin{tabular}{|c|c|c|c|c|}
\hline \multirow[b]{2}{*}{$C_{s}$} & \multicolumn{2}{|c|}{$\mathrm{C}-\mathrm{F}$} & \multicolumn{2}{|c|}{ S-S } \\
\hline & $\begin{array}{c}45^{\circ} / 0^{\circ} / 45^{\circ} \\
\mathrm{KE} / \mathrm{EGE} / \mathrm{KE}\end{array}$ & $\begin{array}{c}45^{\circ} / 60^{\circ} / 0^{\circ} / 60^{\circ} / 45^{\circ} \\
\text { KE/EGE/GE/EGE/KE }\end{array}$ & $\begin{array}{c}45^{\circ} / 0^{\circ} / 45^{\circ} \\
\mathrm{KE} / \mathrm{EGE} / \mathrm{KE}\end{array}$ & $\begin{array}{c}45^{\circ} / 60^{\circ} / 0^{\circ} / 60^{\circ} / 45^{\circ} \\
\text { KE/EGE/GE/EGE/KE }\end{array}$ \\
\hline-0.5 & 0.165313 & 0.156536 & 0.443432 & 0.375673 \\
\hline-0.3 & 0.076568 & 0.075873 & 0.436273 & 0.380052 \\
\hline-0.1 & 0.098835 & 0.095561 & 0.444782 & 0.385077 \\
\hline 0.1 & 0.120564 & 0.115250 & 0.448693 & 0.385777 \\
\hline 0.3 & 0.142597 & 0.135491 & 0.448082 & 0.382432 \\
\hline 0.5 & 0.165313 & 0.156536 & 0.443432 & 0.375673 \\
\hline
\end{tabular}

orientations and the angular frequency value differs for different material combinations.

Effect of length ratio on the fundamental angular frequency value of five-layered shells with different material combinations and ply orientations is shown in Figure 9 for S-S boundary conditions. It can be seen from Figures 9(a)-9(c) that different ply angles negligibly affect fundamental angular frequency value. Moreover, material combination GE/EGE/KE/EGE/GE shows highest frequency followed by $\mathrm{KE} / \mathrm{EGE} / \mathrm{GE} / \mathrm{EGE} / \mathrm{KE}$ and $\mathrm{EGE} / \mathrm{GE} / \mathrm{KE} / \mathrm{GE} /$ EGE material combinations.

Variation of fundamental angular frequency with respect to length ratio for five-layered shells having different material combination is shown in Figure 10 for S-S boundary condition. It is observed that the angular frequency value increases with the increase of length ratio. Further, material combination GE/EGE/KE/EGE/GE shows highest frequency and EGE/GE/KE/GE/EGE shows the lowest frequency.

Three-layered shells with $45^{\circ} / 0^{\circ} / 45^{\circ}$ ply angles and three different material combinations are studied in Figure 11 to examine the effect of length ratio on the fundamental angular frequency value under S-S boundary conditions. It is observed that material combination GE/KE/GE shows highest frequency followed by GE/EGE/GE and KE/EGE/ KE. 


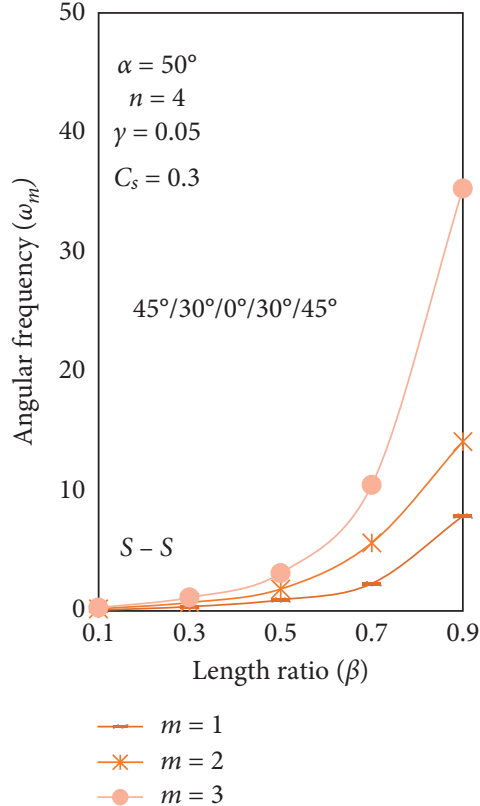

(a)

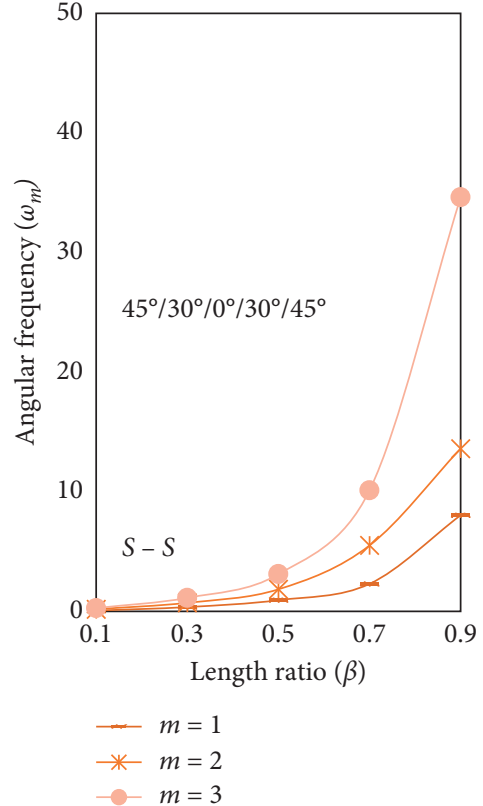

(b)

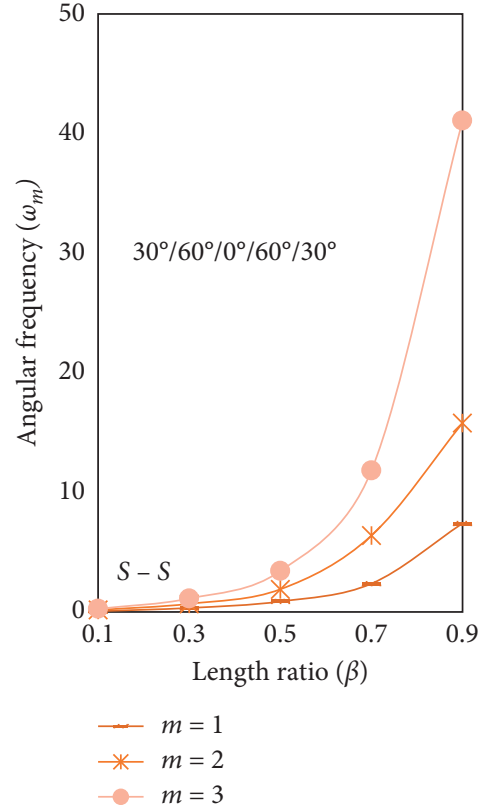

(c)

FIGURE 2: Influence of length ratio on the angular frequency of five-layered conical shells with KE/EGE/GE/EGE/KE material combination.

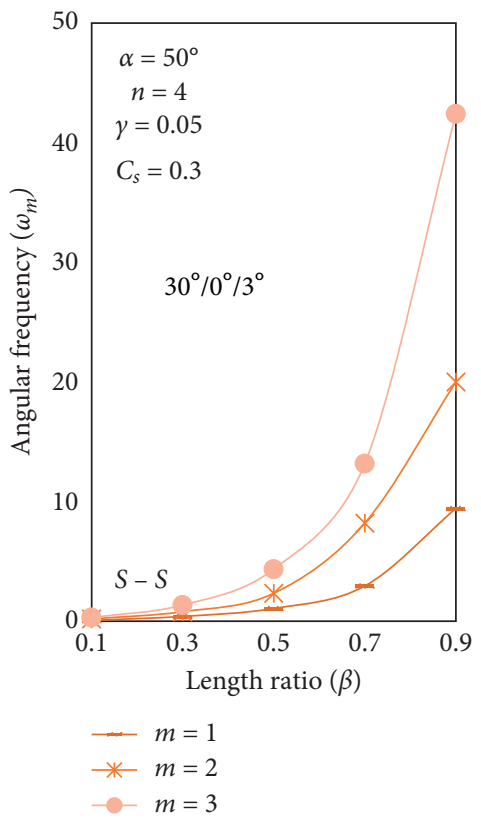

(a)

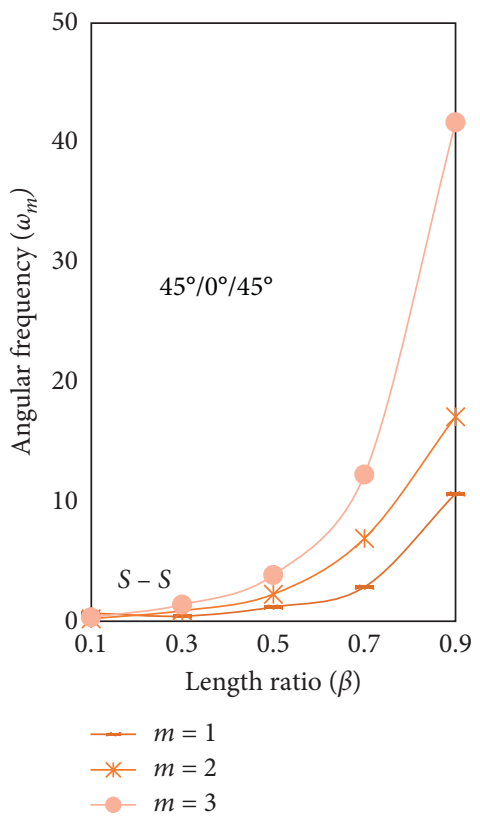

(b)

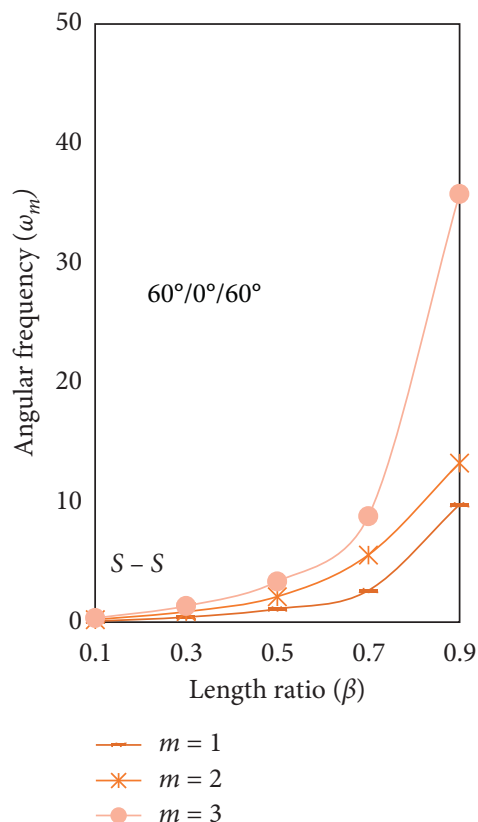

(c)

FIGURE 3: Influence of length ratio on the angular frequency of three-layered conical shells with GE/EGE/GE material combination.

Figure 12 depicts the fundamental angular frequency variation with respect to length ratio for three-layered shells under C-F boundary conditions. The characteristic pattern of curve is similar to that in Figure 10, whereas the frequency value decreases under C-F boundary condition as compared to S-S boundary condition.

The effect of different material combination of fivelayered shells on the fundamental angular frequency is shown in Figure 13 for C-F boundary conditions. The characteristic pattern of curve is similar to that in Figure 12. The frequency value is highest for GE/EGE/KE/EGE/GE material combination.

The variation of fundamental angular frequency $\omega_{m}(m=$ $1,2,3)$ with length ratio $\beta$ for three-layered conical shell under C-F boundary conditions is shown in Figures 14(a) for GE/ EGE/GE, 14(b) for GE/KE/GE, and 14(c) for KE/EGE/KE 


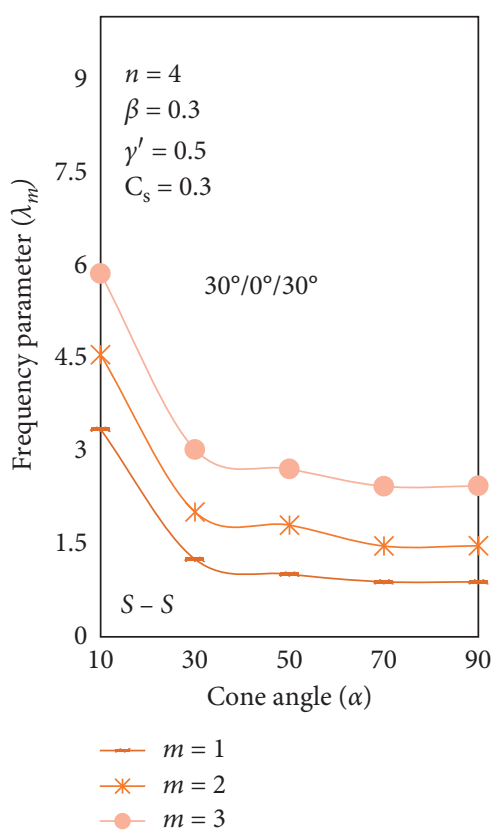

(a)

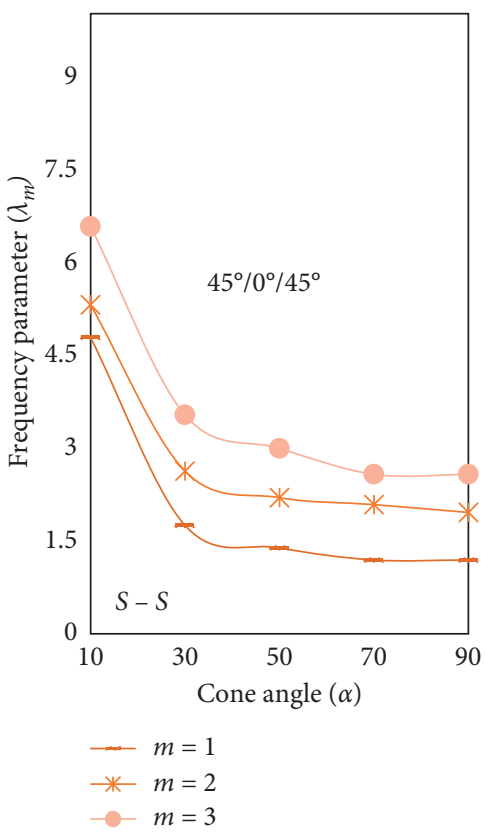

(b)

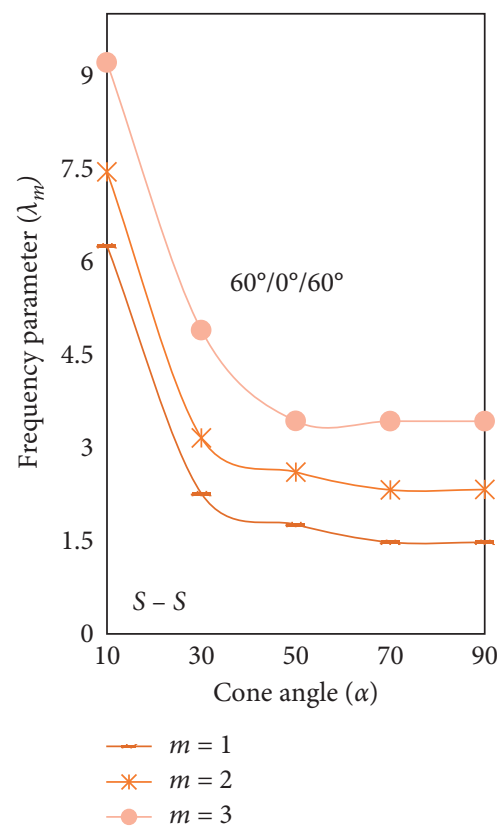

(c)

FIGURE 4: Influence of cone angle on the frequency parameter of three-layered conical shells with GE/EGE/GE material combination.

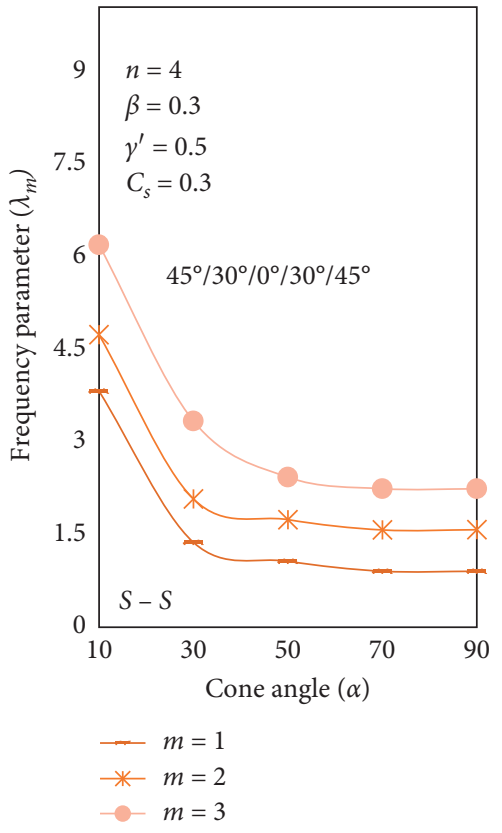

(a)

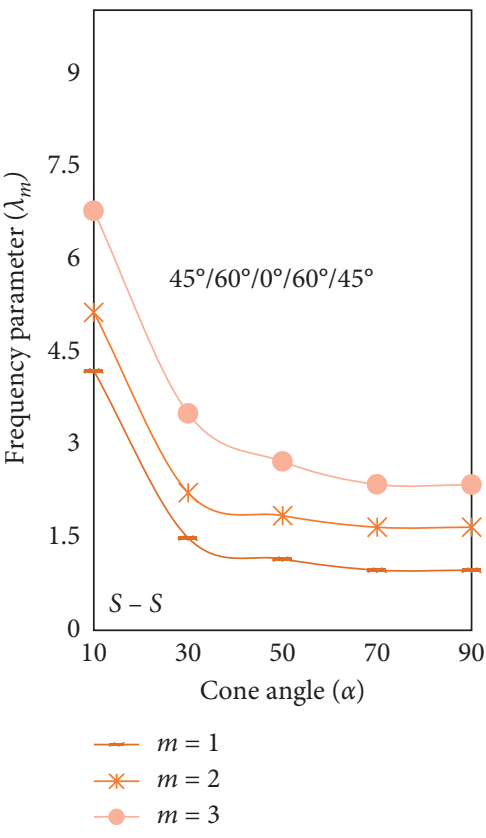

(b)

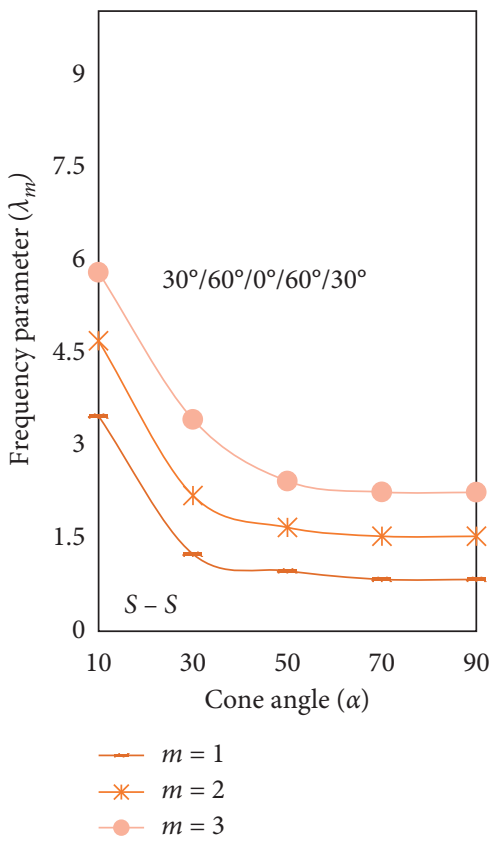

(c)

FIGURE 5: Influence of cone angle on the frequency parameter of five-layered conical shells with KE/EGE/GE/EGE/GE material combination.

material combinations. It is seen that angular frequency value is highest for $30^{\circ} / 0^{\circ} / 30^{\circ}>45^{\circ} / 0^{\circ} / 45^{\circ}>60^{\circ} / 0^{\circ} / 60^{\circ}$ for all three combinations. For material combinations, the angular frequency value is $\mathrm{GE} / \mathrm{KE} / \mathrm{GE}>\mathrm{GE} / \mathrm{EGE} / \mathrm{GE}>\mathrm{KE} /$ $\mathrm{EGE} / \mathrm{KE}$.
Figure 15 shows the influence of cone angle on the fundamental frequency parameter of five-layered shells having different material combinations and lamination schemes under C-F boundary conditions. It is seen that angular frequency value is highest for EGE/GE/KE/GE/EGE 


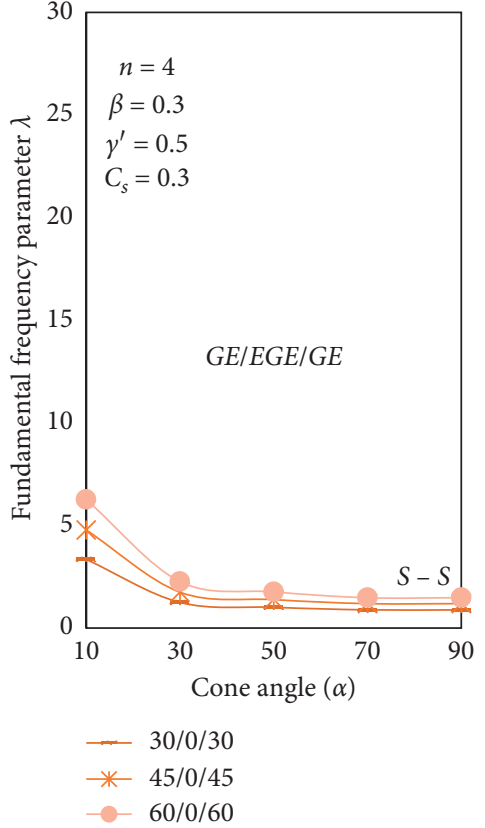

(a)

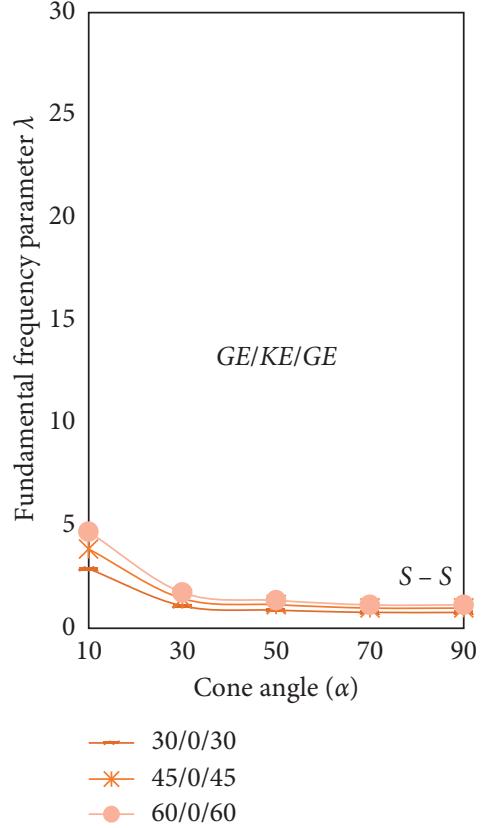

(b)

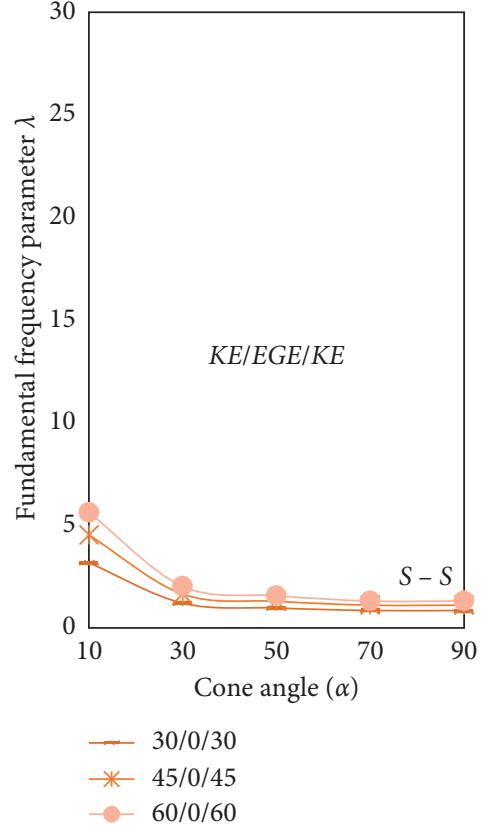

(c)

FiguRe 6: Influence of cone angle on the fundamental frequency parameter of three-layered conical shells with different material combinations.

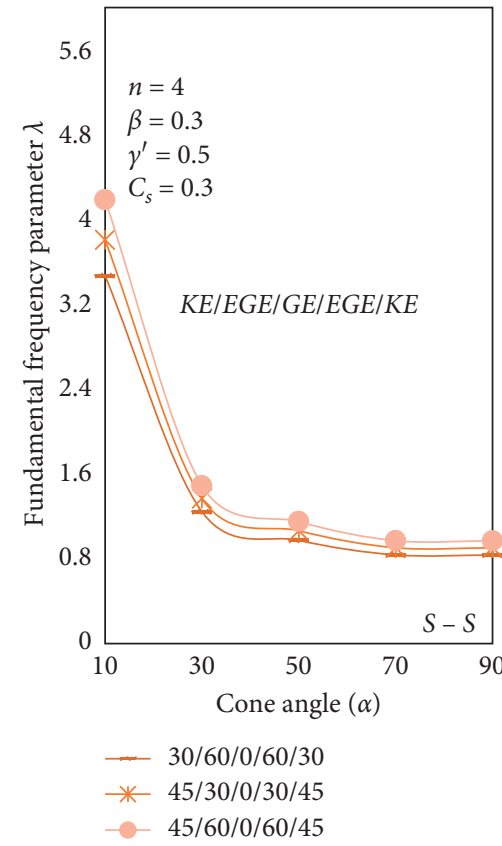

(a)

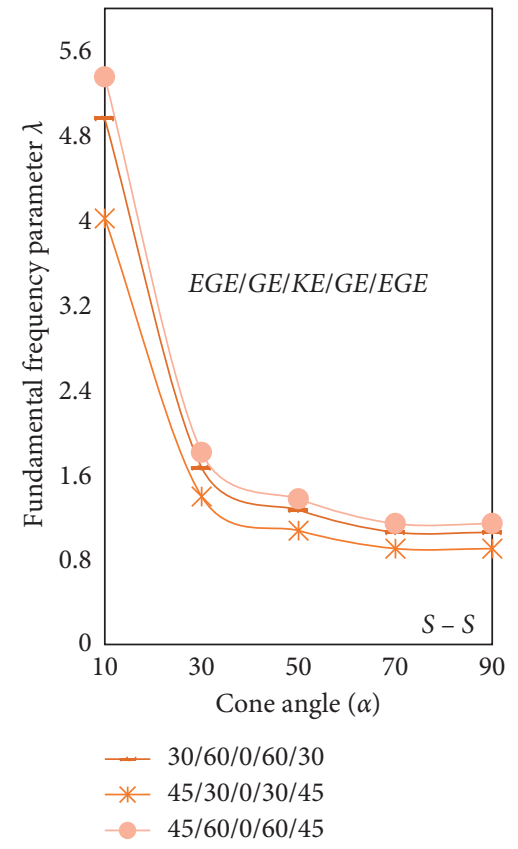

(b)

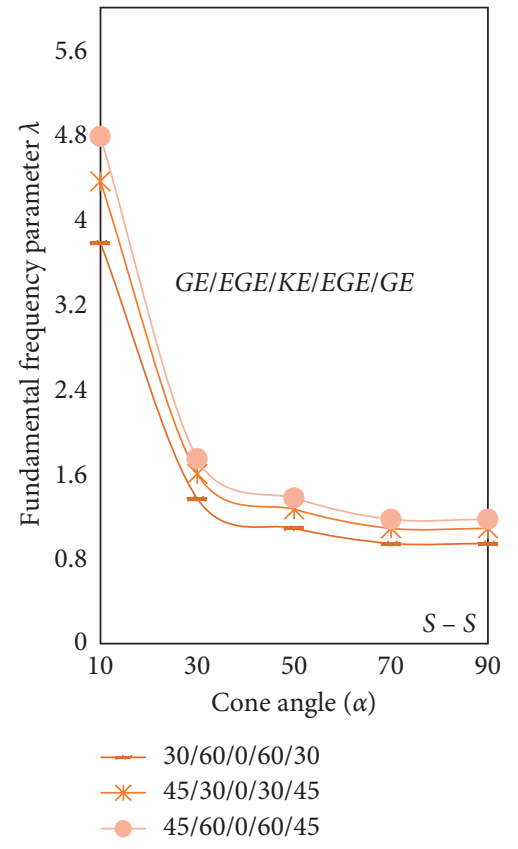

(c)

Figure 7: Influence of cone angle on the fundamental frequency parameter of five-layered conical shells with different material combinations.

followed by GE/EGE/KE/EGE/GE and KE/EGE/GE/EGE/ $\mathrm{KE}$. The difference in the fundamental frequency parameter value is very small for three different lamination schemes.

The effect of circumferential node number $n$ on the frequency parameter $\lambda_{m}$ of five-layered shells having material combination KE/EGE/GE/EGE/KE for S-S boundary conditions is shown in Figure 16. The parameters $\beta=0.5$, $\gamma=0.05, \alpha=30^{\circ}$, and $C_{s}=0.5$ are fixed. Different lamination schemes, (a) $30^{\circ} / 60^{\circ} / 0^{\circ} / 60^{\circ} / 30^{\circ}$, (b) $45^{\circ} / 30^{\circ} / 0^{\circ} / 30^{\circ} / 45^{\circ}$, and (c) $45^{\circ} / 60^{\circ} / 0^{\circ} / 60^{\circ} / 45^{\circ}$, are used. It is seen that there is negligible 


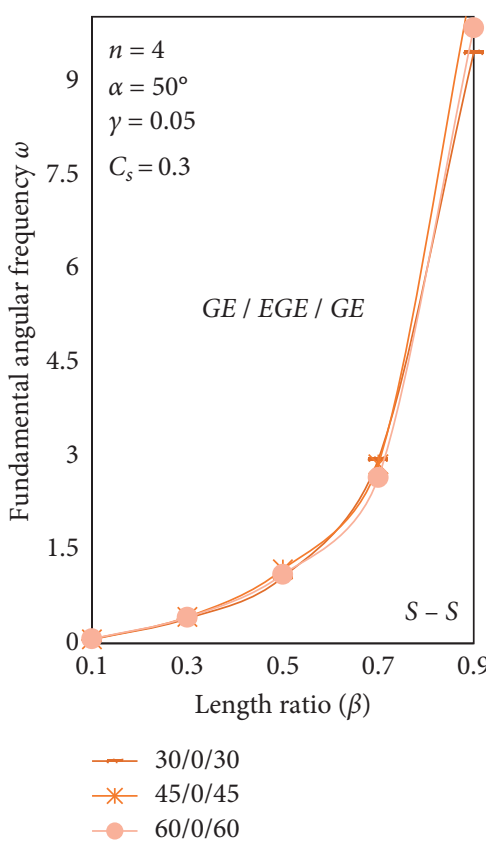

(a)

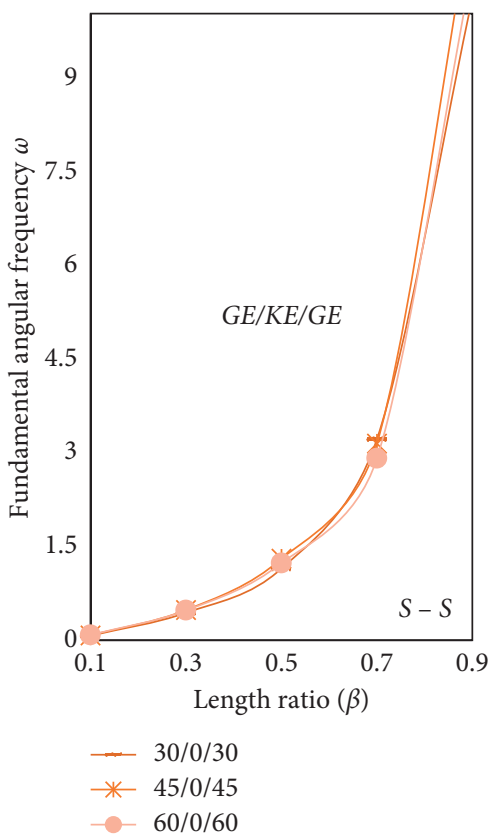

(b)

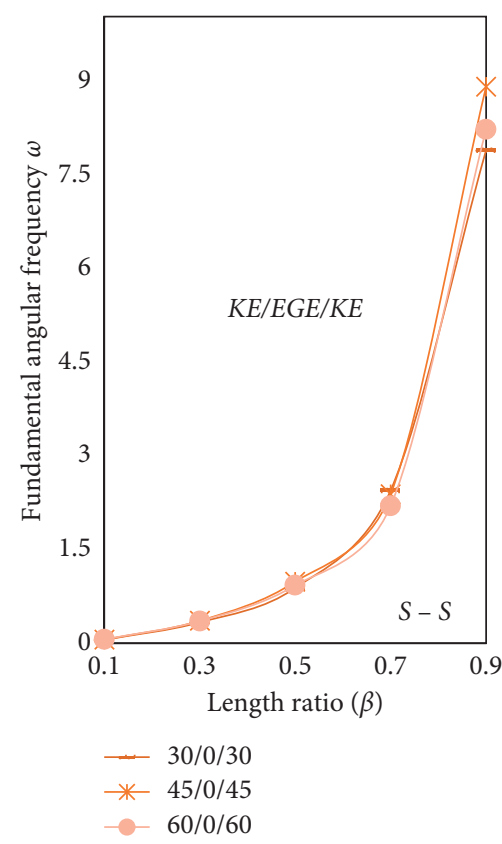

(c)

Figure 8: Influence of length ratio on the fundamental angular frequency of three-layered conical shells with different material combinations.

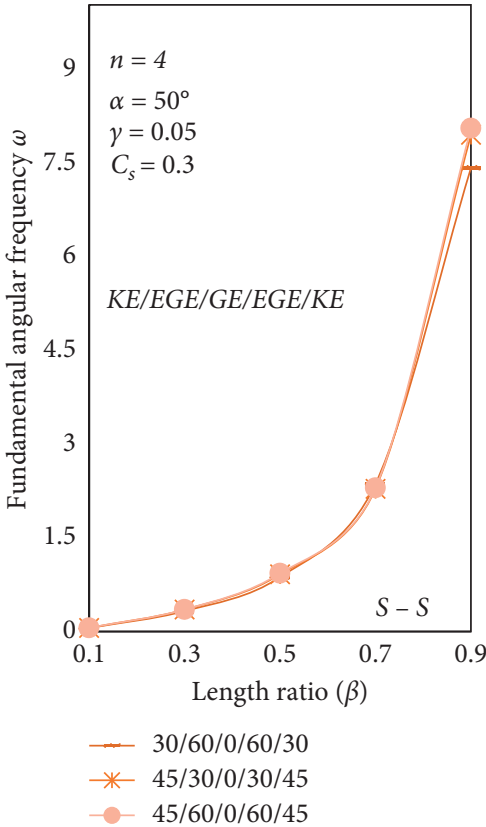

(a)

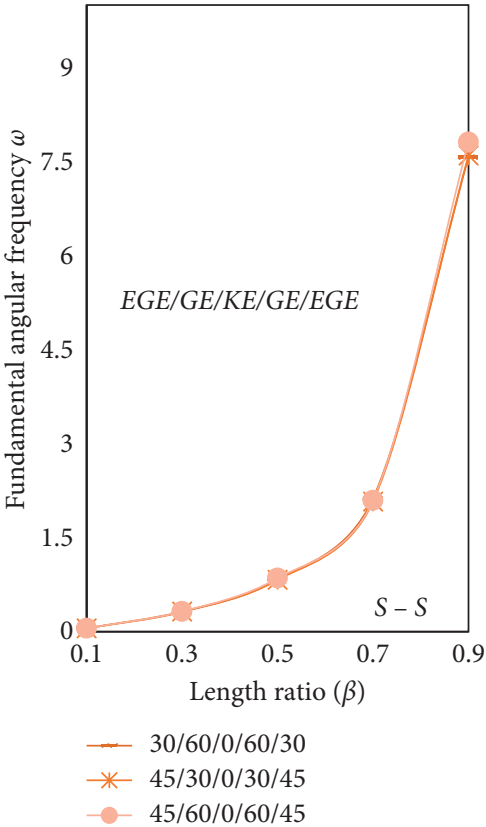

(b)

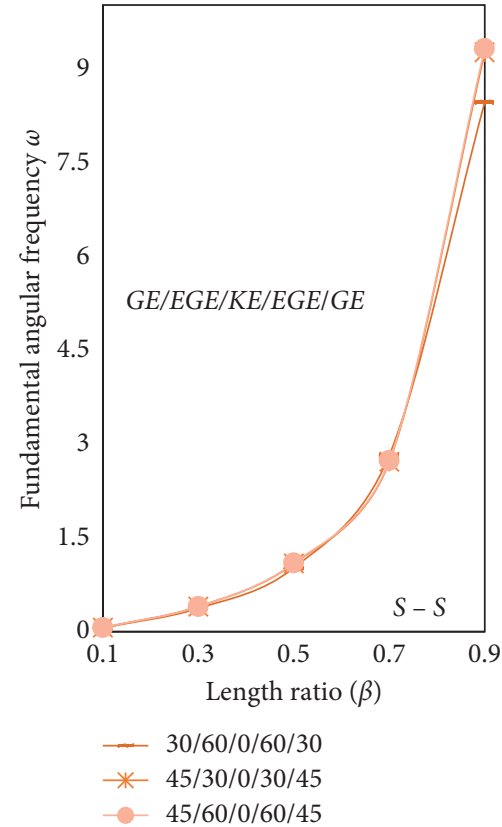

(c)

Figure 9: Influence of length ratio on the fundamental angular frequency of five-layered conical shells with different material combinations.

effect of different lamination schemes on the frequency parameter value. Moreover, the frequency parameter value for $\lambda_{1}$ and $\lambda_{2}$ differs within $1<n<5$ and increases steadily afterwards. Meanwhile frequency parameter value for $\lambda_{3}$ increases steadily as the circumferential node number increases.
Figure 17 depicts the variation of frequency parameter value with respect to circumferential node number for $\mathrm{C}-\mathrm{F}$ boundary condition. It is seen from Figures 16 and 17 that the frequency parameter value decreases under C-F boundary condition as compared to S-S boundary condition. 


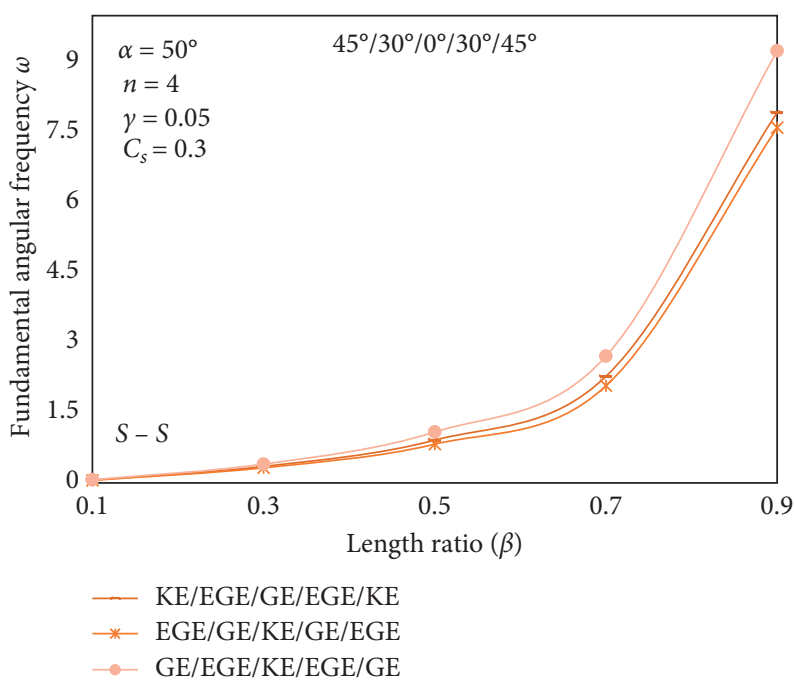

FIGURE 10: Influence of length ratio on the fundamental angular frequency of five-layered conical shells with different material combinations.

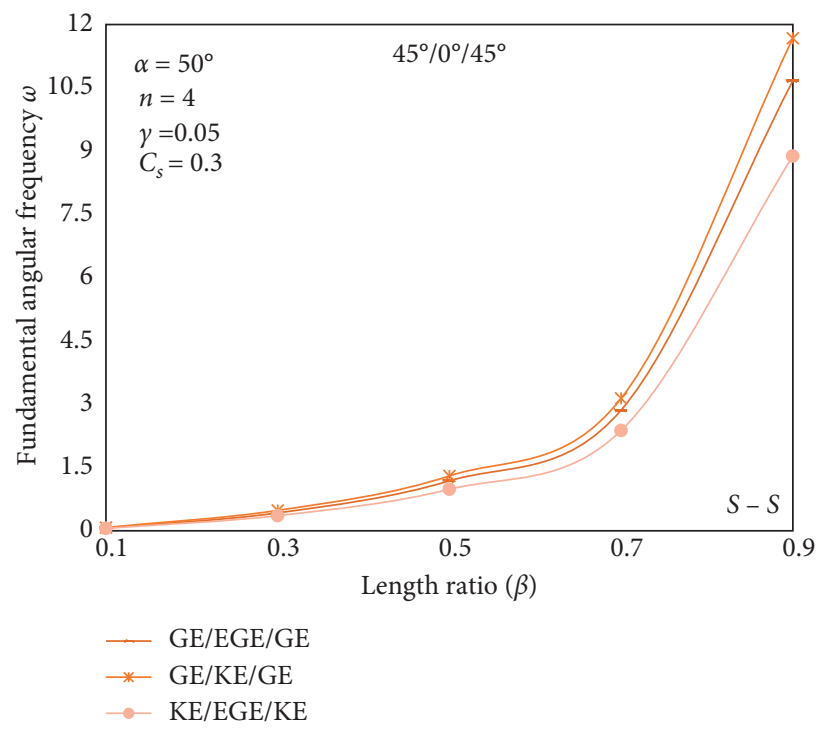

FIGURE 11: Influence of length ratio on the fundamental angular frequency of three-layered conical shells with different material combinations.

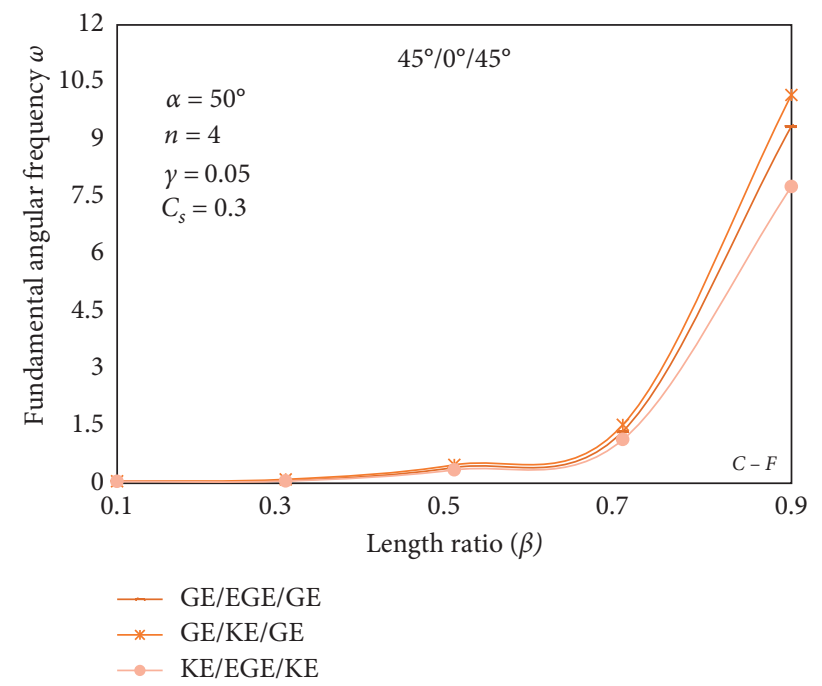

FIGURE 12: Influence of length ratio on the fundamental angular frequency of three-layered conical shells with different material combinations. 


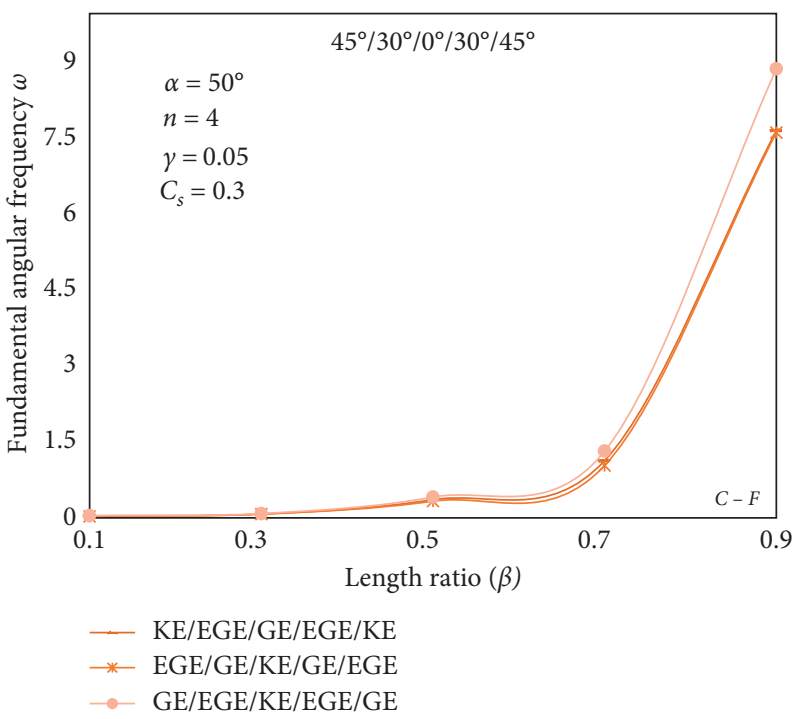

FIGURE 13: Influence of length ratio on the fundamental angular frequency of five-layered conical shells with different material combinations.

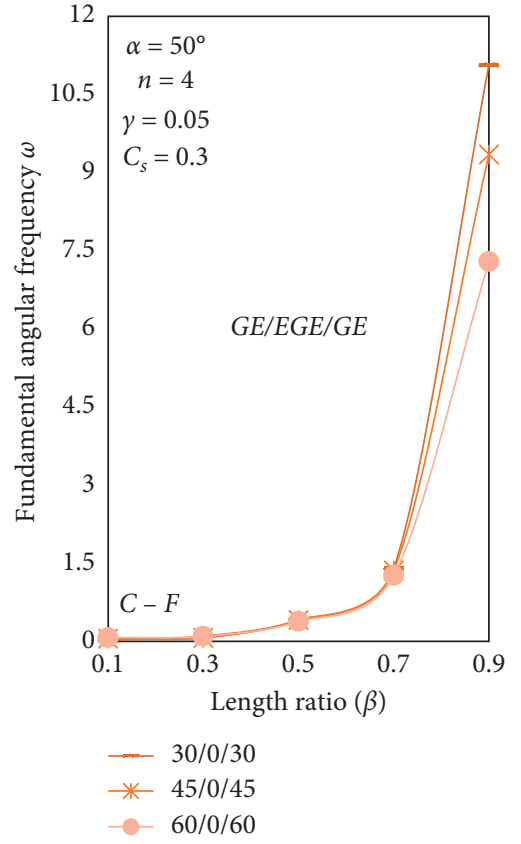

(a)

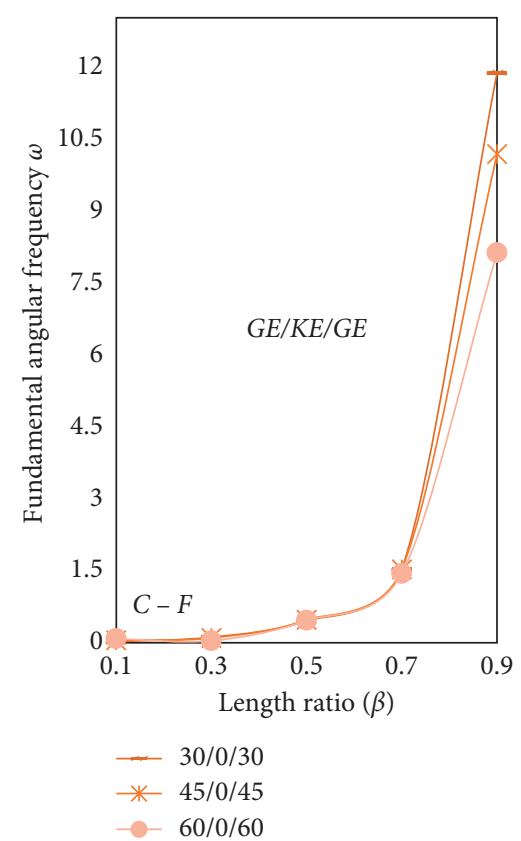

(b)

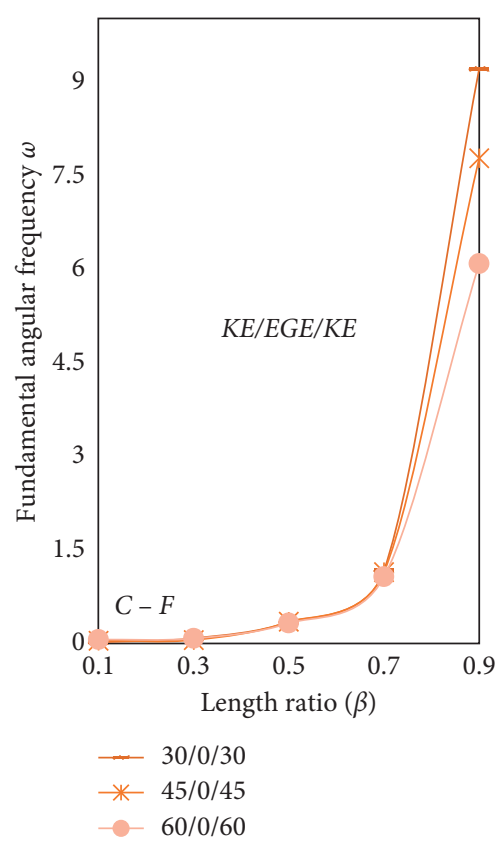

(c)

FIGURE 14: Influence of length ratio on the fundamental angular frequency of three-layered conical shells with different material combinations.

Figures 18(a)-18(c) exhibit the mode shapes for displacement function $W$ of symmetric angle-ply conical shells of material combinations EGE/GE/KE/GE/EGE and ply orientation of $30^{\circ} / 60^{\circ} / 0^{\circ} / 60^{\circ} / 30^{\circ}$. Normalization is done with respect to the maximum transverse displacement $W$. As expected, the transverse displacements are mostly predominant. 


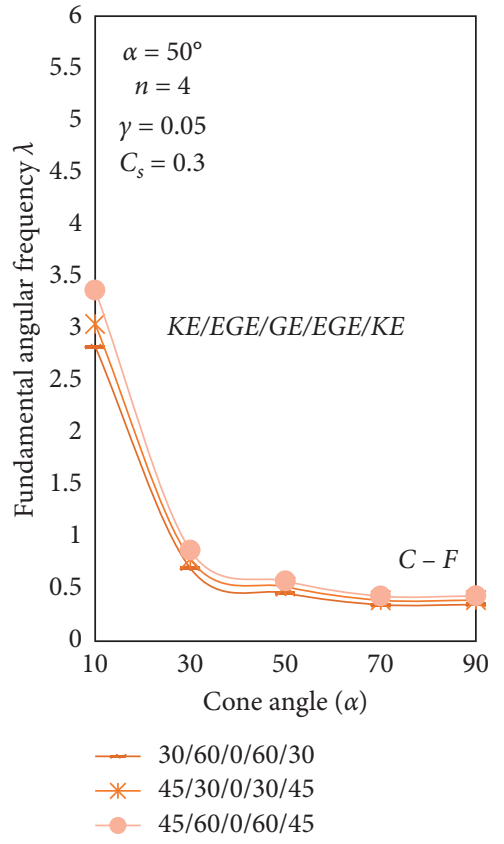

(a)

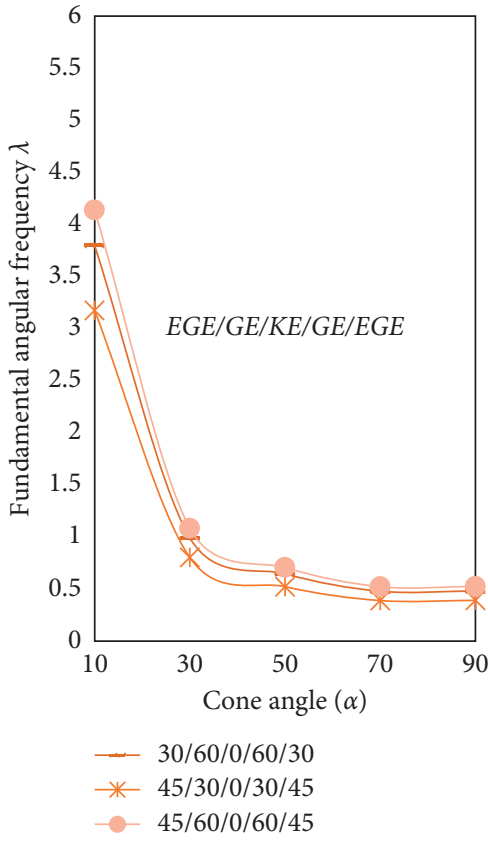

(b)

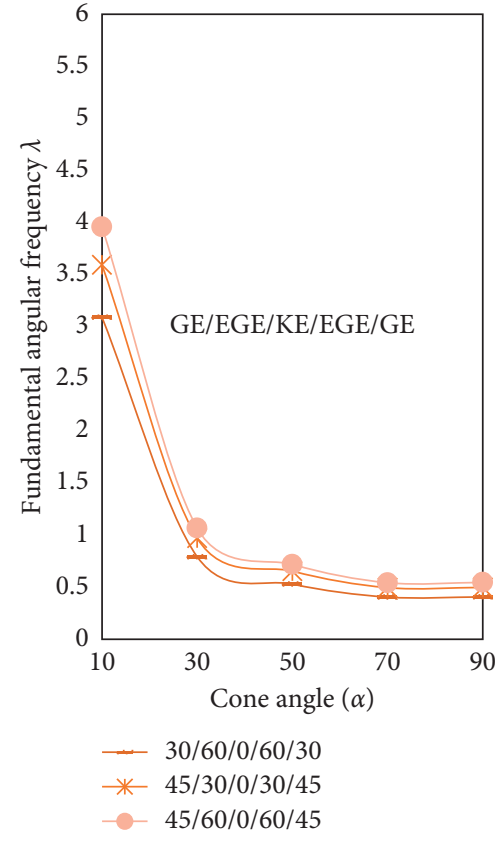

(c)

FIGURE 15: Influence of cone angle on the fundamental frequency parameter of five-layered conical shells with different material combinations.

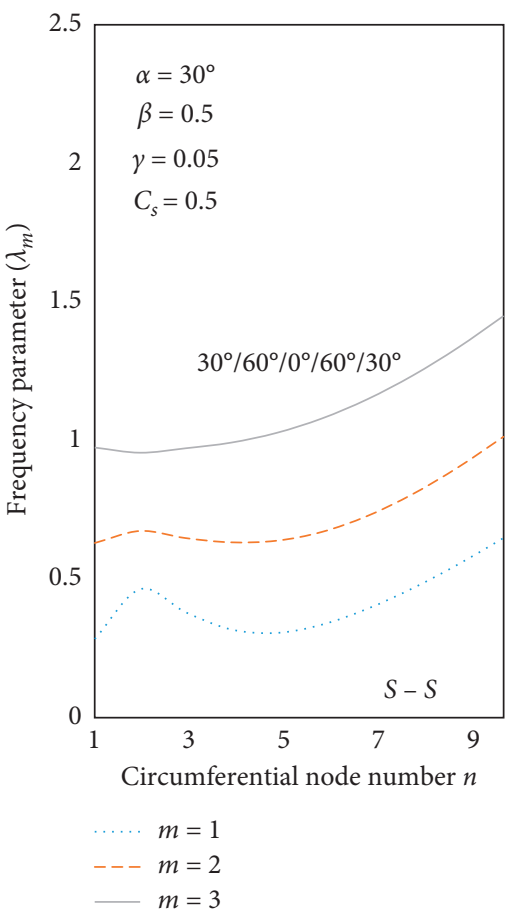

(a)

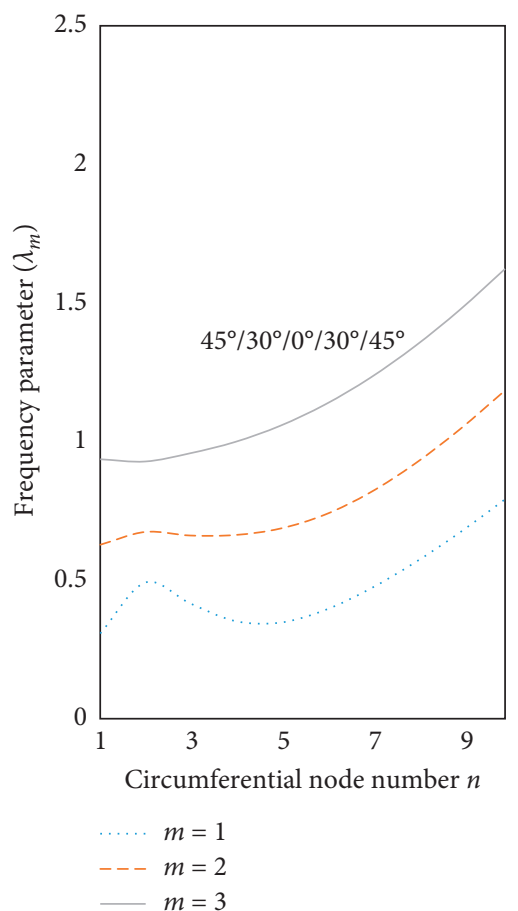

(b)

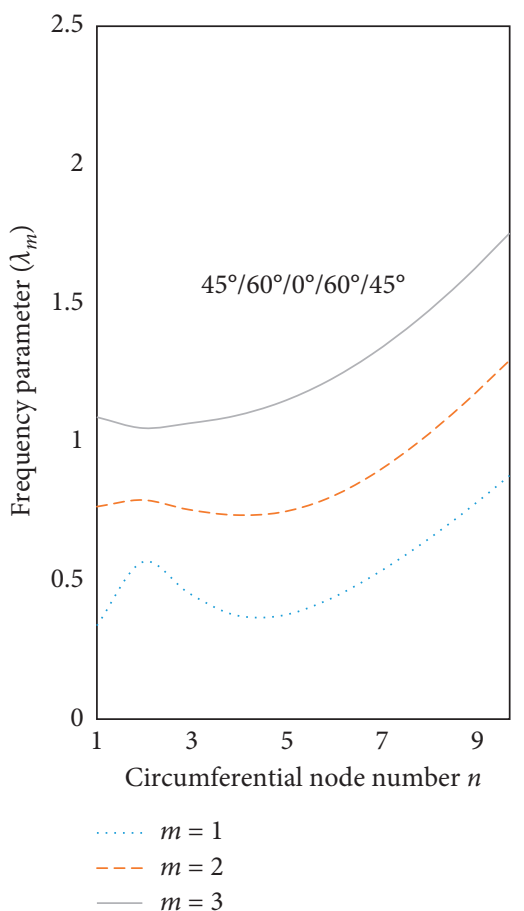

(c)

FIGURE 16: Influence of circumferential node number on the frequency parameter of five-layered conical shells with KE/EGE/GE/EGE/KE material combination. 


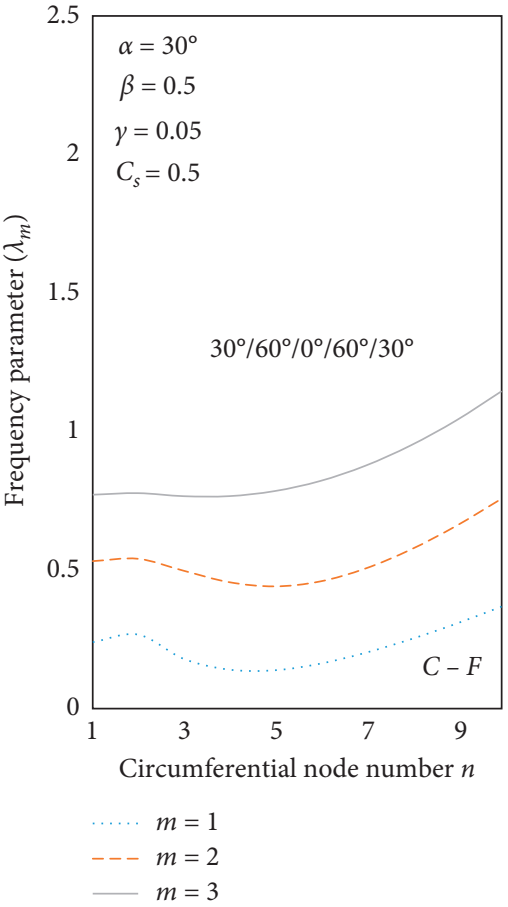

(a)

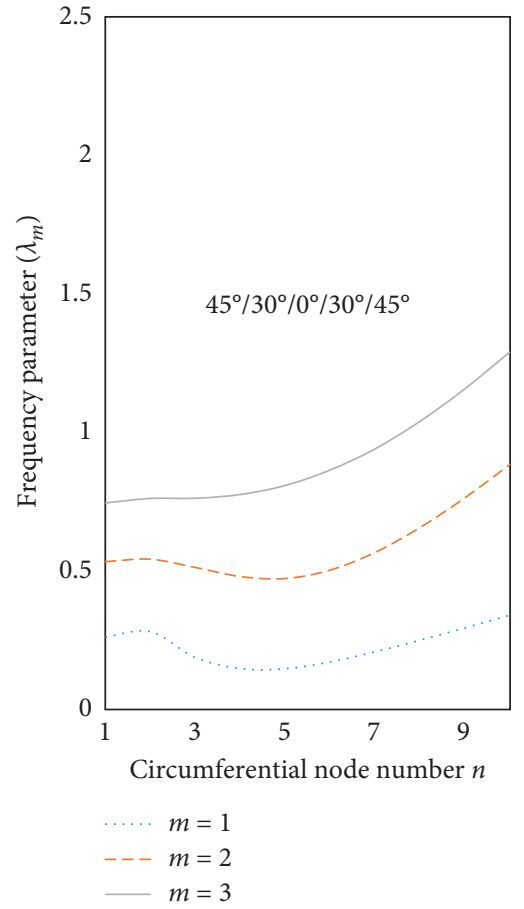

(b)

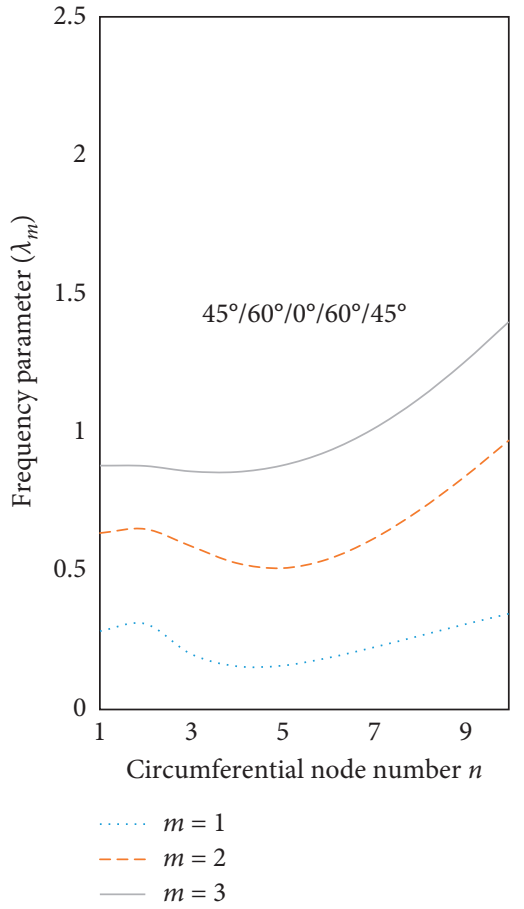

(c)

FIGURE 17: Influence of circumferential node number on the frequency parameter of five-layered conical shells with KE/EGE/GE/EGE/KE material combination.

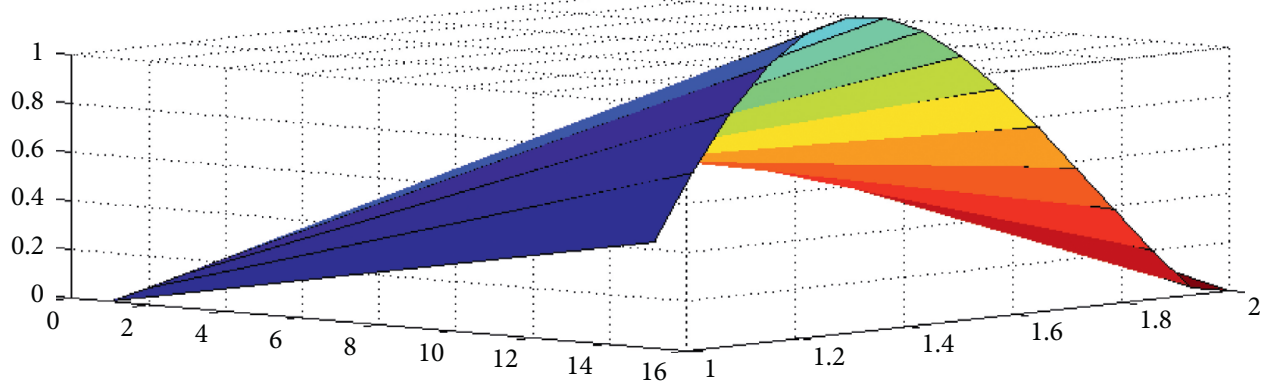

(a)

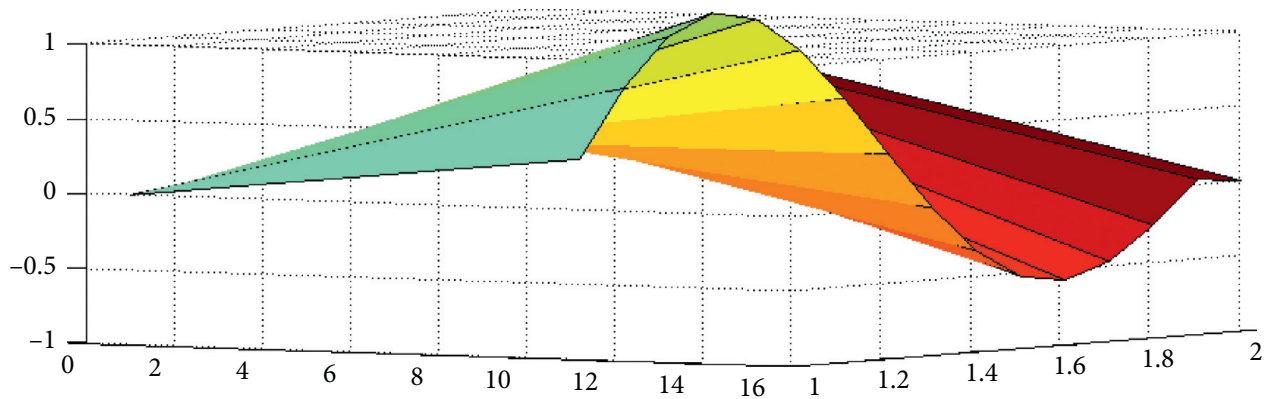

(b)

Figure 18: Continued. 


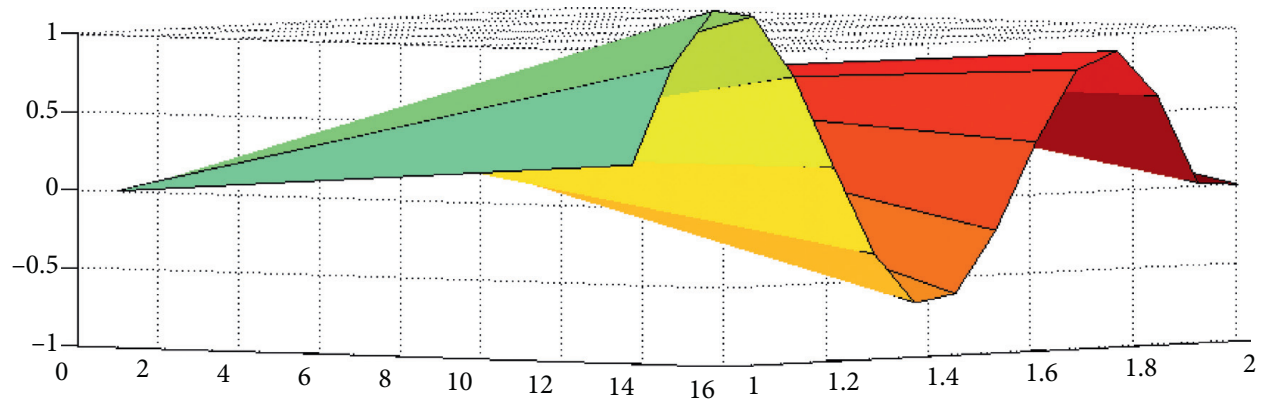

(c)

Figure 18: Mode shapes of vibration of symmetric angle-ply conical shell. (a) Mode 1. (b) Mode 2. (c) Mode 3.

\section{Conclusion}

The free vibration of symmetric angle-ply composite conical shells of variable thickness is analysed, including the effect of shear deformation. The equations of symmetric angle-ply conical shells of variable thickness were derived for simply supported and clamped-free boundary conditions.

The manners of variation of the eigenfrequencies with respect to length ratio, ply angle, and thickness variation under two types of edge conditions are studied. Three- and five-layered shells consisting of three different materials and plies are arranged in symmetric manner and their effects on the frequency parameter are studied and presented.

The frequency values tend to increase, in general, with increase of the length ratio and circumferential node number of the shell. The increase in frequency shows that the rigidity of the structure increases. Meanwhile, frequency values tend to decrease with the increase of cone angle. Besides, the frequency parameter values remain almost the same with respect to sinusoidal variation. In case of ply angle variation, the value of frequency parameter decreases as the number of layers increases. Further, the frequency parameter values are higher when the support conditions are simply supported as compared to clamped-free conditions. Therefore, results depict that the stiffness of the structures decreases or increases as value of $\lambda_{m}$ decreases or increases.

The study has also brought out the elegance and usefulness of the spline function collocation method of solution for boundary value problems of the type discussed.

\section{Conflicts of Interest}

The authors declare that there are no conflicts of interest regarding the publication of this paper.

\section{Acknowledgments}

The authors thankfully acknowledge the Deanship of Scientific Research at King Faisal University, Saudi Arabia, for the financial support under Nasher Track (Grant no. 186353).

\section{References}

[1] J. H. Kang, "Vibrations of complex shells with variable thickness," Journal of Engineering Mechanics, vol. 143, no. 8, Article ID 04017053, 2017.
[2] Q. Cao, Q. Dai, and Y. Chen, "Free vibration analysis of truncated circular conical shells with variable thickness using the Haar wavelet method," Journal of Vibroengineering, vol. 18, no. 8, pp. 5291-5305, 2016.

[3] M. Akbari, Y. Kiani, M. M. Aghdam, and M. R. Eslami, "Free vibration of FGM Lévy conical panels," Composite Structures, vol. 116, pp. 732-746, 2014.

[4] M. Bacciocchi, M. Eisenberger, N. Fantuzzi, F. Tornabene, and E. Viola, "Vibration analysis of variable thickness plates and shells by the generalized differential quadrature method," Composite Structures, vol. 156, pp. 218-237, 2016.

[5] R. Ansari, M. Faghih Shojaei, H. Rouhi, and M. Hosseinzadeh, "A novel variational numerical method for analyzing the free vibration of composite conical shells," Applied Mathematical Modelling, vol. 39, no. 10-11, pp. 2849-2860, 2015.

[6] A. Asanjarani, S. Satouri, A. Alizadeh, and M. Kargarnovin, "Free vibration analysis of 2D-FGM truncated conical shell resting on Winkler-Pasternak foundations based on FSDT," Proceedings of the Institution of Mechanical Engineers, Part C: Journal of Mechanical Engineering Science, vol. 229, no. 5, pp. 818-839, 2015.

[7] S. Wu, Y. Qu, and H. Hua, "Free vibration of laminated orthotropic conical shell on Pasternak foundation by a domain decomposition method," Journal of Composite Materials, vol. 49, no. 1, pp. 35-52, 2015.

[8] M. Liu, J. Liu, and Y. Cheng, "Free vibration of a fluid loaded ring-stiffened conical shell with variable thickness," Journal of Vibration and Acoustics, vol. 136, no. 5, Article ID 051003, 2014.

[9] M. Z. Nejad, M. Jabbari, and M. Ghannad, "Elastic analysis of FGM rotating thick truncated conical shells with axiallyvarying properties under non-uniform pressure loading," Composite Structures, vol. 122, pp. 561-569, 2015.

[10] Ö. Civalek, "Vibration analysis of laminated composite conical shells by the method of discrete singular convolution based on the shear deformation theory," Composites Part B: Engineering, vol. 45, no. 1, pp. 1001-1009, 2013.

[11] M. Shakouri and M. A. Kouchakzadeh, "Free vibration analysis of joined conical shells: analytical and experimental study," Thin-Walled Structures, vol. 85, pp. 350-358, 2014.

[12] A. H. Sofiyev and N. Kuruoglu, "On the solution of the buckling problem of functionally graded truncated conical shells with mixed boundary conditions," Composite Structures, vol. 123, pp. 282-291, 2015.

[13] K. K. Viswanathan, Z. A. Aziz, S. Javed, Y. Yaacob, and B. Pullepu, "Free vibration of symmetric angle ply truncated conical shells under different boundary conditions using 
spline method," Journal of Mechanical Science and Technology, vol. 29, no. 5, pp. 2073-2080, 2015.

[14] K. K. Viswanathan, S. Javed, and Z. A. Aziz, "Free vibration of symmetric angle-ply layered conical shell frusta of variable thickness under shear deformation theory," Structural Engineering and Mechanics, vol. 45, no. 2, pp. 259-275, 2013.

[15] K. K. Viswanathan, S. Javed, K. Prabakar, Z. A. Aziz, and I. Abu Bakar, "Free vibration of anti-symmetric angle-ply laminated conical shells," Composite Structures, vol. 122, pp. 488-495, 2015.

[16] S. Javed, K. K. Viswanathan, Z. A. Aziz, and J. H. Lee, "Vibration analysis of a shear deformed anti-symmetric angle-ply conical shells with varying sinusoidal thickness," Structural Engineering and Mechanics, vol. 58, no. 6, pp. 1001-1020, 2016.

[17] S. Javed, K. K. Viswanathan, Z. A. Aziz, and K. Prabakar, "Free vibration of anti-symmetric angle-ply plates with variable thickness," Composite Structures, vol. 137, pp. 56-69, 2016.

[18] X. Xie, G. Jin, T. Ye, and Z. Liu, "Free vibration analysis of functionally graded conical shells and annular plates using the Haar wavelet method," Applied Acoustics, vol. 85, pp. 130-142, 2014.

[19] X. Ma, G. Jin, Y. Xiong, and Z. Liu, "Free and forced vibration analysis of coupled conical-cylindrical shells with arbitrary boundary conditions," International Journal of Mechanical Sciences, vol. 88, pp. 122-137, 2014.

[20] Q. Wang, D. Shi, F. Pang, and Q. Liang, "Vibrations of composite laminated circular panels and shells of revolution with general elastic boundary conditions via Fourier-Ritz method," Curved and Layered Structures, vol. 3, no. 1, pp. 105-136, 2016.

[21] Z. Su, G. Jin, and T. Ye, “Three-dimensional vibration analysis of thick functionally graded conical, cylindrical shell and annular plate structures with arbitrary elastic restraints," Composite Structures, vol. 118, pp. 432-447, 2014.

[22] X. Wang, W. Wu, and X. Yao, "Structural and acoustic response of a finite stiffened conical shell," Acta Mechanica Solida Sinica, vol. 28, no. 2, pp. 200-209, 2015.

[23] Y. Qu, X. Long, S. Wu, and G. Meng, "A unified formulation for vibration analysis of composite laminated shells of revolution including shear deformation and rotary inertia," Composite Structures, vol. 98, pp. 169-191, 2013.

[24] C.-P. Wu and C.-Y. Lee, "Differential quadrature solution for the free vibration analysis of laminated conical shells with variable stiffness," International Journal of Mechanical Sciences, vol. 43, no. 8, pp. 1853-1869, 2001.

[25] K. R. Sivadas and N. Ganesan, "Vibration analysis of laminated conical shells with variable thickness," Journal of Sound and Vibration, vol. 148, no. 3, pp. 477-491, 1991.

[26] D. Featherston and M. Barabasz, "Loudspeaker response improvement using cone thickness variation," Journal of the Audio Engineering Society, vol. 48, no. 12, pp. 1216-1220, 2000.

[27] R. U. Nair and R. Jha, "EM performance analysis of an A-sandwich cone-ogive hybrid variable thickness radome," in Proceedings of the 2004 IEEE Antennas and Propagation Society International Symposium, IEEE, Monterey, CA, USA, June 2004.

[28] G. Hauver, N. Huffington, K. Kimsey, L. Magness, and G. Randers-Pehrson, "Material modeling for terminal ballistic simulation," Technical report BRL-TR-3392, US Army Ballistic Research Laboratory, Aberdeen, MD, USA, 1992.

[29] K. Viswanathan and S. Javed, "Free vibration of anti-symmetric angle-ply cylindrical shell walls using first-order shear deformation theory," Journal of Vibration and Control, vol. 22, no. 7, pp. 1757-1768, 2016.

[30] K. K. Viswanathan, J. H. Lee, Z. A. Aziz, I. Hossain, W. Rongqiao, and H. Y. Abdullah, "Vibration analysis of cross-ply laminated truncated conical shells using a spline method," Journal of Engineering Mathematics, vol. 76, no. 1, pp. 139-156, 2012.

[31] M. H. Toorani and A. A. Lakis, "General equations of anisotropic plates and shells including transverse shear deformations, rotary inertia and initial curvature effects," Journal of Sound and Vibration, vol. 237, no. 4, pp. 561-615, 2000.

[32] K. K. Viswanathan and S.-K. Lee, "Free vibration of laminated cross-ply plates including shear deformation by spline method," International Journal of Mechanical Sciences, vol. 49, no. 3, pp. 352-363, 2007. 